1

\title{
Genomes of novel Myxococcota reveal severely curtailed machineries for predation and cellular differentiation
}

\section{Chelsea L. Murphy', R. Yang1, T. Decker ${ }^{1}$, C. Cavalliere $^{1}$, V. Andreev ${ }^{2}$, N. Bircher ${ }^{1}$, J.} Cornell $^{1}$, R. Dohmen ${ }^{1}$, C. J. Pratt ${ }^{3}$, A. Grinnell ${ }^{1}$, J. Higgs ${ }^{1}$, C. Jett ${ }^{1}$, E. Gillett ${ }^{1}$, R. Khadka ${ }^{1}$, S. Mares $^{1}$, C. Meili ${ }^{1}$, J. Liu ${ }^{4}$, H. Mukhtar ${ }^{1}$, Mostafa S. Elshahed ${ }^{1}$, and Noha H. Youssef ${ }^{1 *}$

${ }^{\mathbf{1}}$ Department of Microbiology and Molecular Genetics, ${ }^{2}$ Department of Plant Biology, Ecology, and Evolution, ${ }^{3}$ Department of Entomology and Plant Pathology, and ${ }^{4}$ Department of Animal Sciences, Oklahoma State University, Stillwater, OK, USA

Running Title: Non-social anaerobic Myxococcota

*: Corresponding author: Mailing address: Oklahoma State University, Department of Microbiology and Molecular Genetics, 1110 S Innovation Way, Stillwater, OK 74074. Phone: (405) 744-1192, Fax: (405) 744-1112. Email: noha@ okstate.edu. 


\section{Abstract}

43 Cultured Myxococcota are predominantly aerobic soil inhabitants, characterized by their highly

44 coordinated predation and cellular differentiation capacities. Little is currently known regarding

45 yet-uncultured Myxococcota from anaerobic, non-soil habitats. We analyzed genomes

46 representing one novel order (o__JAFGXQ01) and one novel family ( $f$ __JAFGIB01) in the

47 Myxococcota from an anoxic freshwater spring in Oklahoma, USA. Compared to their soil

48 counterparts, anaerobic Myxococcota possess smaller genomes, and a smaller number of genes

49 encoding biosynthetic gene clusters (BGCs), peptidases, one- and two-component signal

50 transduction systems, and transcriptional regulators. Detailed analysis of thirteen distinct

51 pathways/processes crucial to predation and cellular differentiation revealed severely curtailed

52 machineries, with the notable absence of homologs for key transcription factors (e.g. FruA and

$53 \mathrm{MrpC}$ ), outer membrane exchange receptor (TraA), and the majority of sporulation-specific and

54 A-motility-specific genes. Further, machine-learning approaches based on a set of 634 genes

55 informative of social lifestyle predicted a non-social behavior for Zodletone Myxococcota.

56 Metabolically, Zodletone Myxococcota genomes lacked aerobic respiratory capacities, but

57 encoded genes suggestive of fermentation, dissimilatory nitrite reduction, and dissimilatory

58 sulfate-reduction (in f_JAFGIB01) for energy acquisition. We propose that predation and cellular

59 differentiation represent a niche adaptation strategy that evolved circa 500 Mya in response to

60 the rise of soil as a distinct habitat on earth. 


\section{Importance}

63 The Myxococcota is a phylogenetically coherent bacterial lineage that exhibits unique social

64 traits. Cultured Myxococcoat are predominantly aerobic soil-dwelling microorganisms that are

65 capable of predation and fruiting body formation. However, multiple yet-uncultured lineages

66 within the Myxococcota has been encountered in a wide range of non-soil, predominantly

67 anaerobic habitats; and the metabolic capabilities, physiological preferences, and capacity of

68 social behavior of such lineages remains unclear. Here, we analyzed genomes recovered from a

69 metagenomic analysis of an anoxic freshwater spring in Oklahoma, USA that represent novel,

70 yet-uncultured, orders and families in the Myxococcota. The genomes appear to lack the

71 characteristic hallmarks for social behavior encountered in Myxococcota genomes, and displayed

72 a significantly smaller genome size and a smaller number of genes encoding biosynthetic gene

73 clusters, peptidases, signal transduction systems, and transcriptional regulators. Such perceived

74 lack of social capacity we confirmed through detailed comparative genomic analysis of thirteen

75 pathways associated with Myxococcota social behavior, as well as the implementation of

76 machine learning approaches to predict social behavior based on genome composition.

77 Metabolically, these novel Myxococcota are predicted to be strict anaerobes, utilizing

78 fermentation, nitrate rductio, and dissimilarity sulfate reduction for energy acquisition. Our result

79 highlight the broad patterns of metabolic diversity within the yet-uncultured Myxococcota and

80 suggest that the evolution of predation and fruiting body formation in the Myxococcoat has

81 occurred in response to soil formation as a distinct habitat on earth. 


\section{Introduction}

The "Myxobacteria" represent a phylogenetically coherent lineage within the Domain

84 Bacteria (1). Originally assigned to the class deltaproteobacteria $(2,3)$, they have recently been

85 recognized as a separate phylum (Myxococcota) based on phylogenomic assessment; a proposal empirically supported by their distinct metabolic, and structural characteristics (4). The

87 Myxococcota are highly social organisms, displaying specific behaviors (predation and fruiting

88 body formation) that require a high level of kin recognition, cell-to-cell communication, and

89 intercellular coordination (5). Indeed, cellular differentiation in the Myxococcota has aptly been

90 described as the most successful foray for a prokaryotic organism into multicellularity (5).

91 Both predation and fruiting body formation processes involve differential gene activation

92 and expression in seemingly equivalent cells, leading to distinct cellular differentiation and

93 disparate fates in response to external environmental stimuli. As predators, model Myxococcota

94 utilize an epibiotic strategy, where swarms of motile cells surround and lyse prey cells via the

95 production of secondary metabolites and extracellular enzymes (6). Significant coordination of

96 motility and lytic agents production between individual cells has been proposed as a means to

97 enhance the efficiency of Myxococcota predator swarms ((7) but see (8)). Cellular differentiation

98 entails the formation of elaborate multicellular structures (fruiting bodies) in response to nutrient

99 depletion (9). The process involves cell aggregation and subsequent differentiation of a subset of

100 cells into resistant myxospores, another subset into peripheral rods on the outside of the fruiting

101 body adapted to rapidly respond to re-appearing nutrients, and a third subset undergoing

102 programmed cell death $(9,10)$.

103 An extensive body of literature, spanning decades on the mechanistic basis of social

104 behavior in model Myxococcota, is available (5, 6, 9, 11-13). Predation is enabled by two types 
105 of gliding motility (individual adventurous (A) motility and cooperative social (S) motility),

106 exopolysaccharide production, secretion of secondary metabolites and extracellular enzymes

107 (proteases and CAZymes), and mechanisms for kin/self-recognition and cheaters elimination (5)

108 (this later is also important during aggregation and fruiting body formation). Starvation-induced

109 cellular differentiation is mediated by four modules of highly interconnected and signal-

110 responsive cascades of signal transduction networks that act sequentially as well as cooperatively

111 to coordinate and time aggregation, fruiting body formation, and sporulation (11).

112 Simultaneously, starvation-induced stringent response prompts the production of extracellular

113 signals (most importantly A-signal, and C-signal) that activate a wide range of transcription

114 factors to facilitate aggregation, regulate the onset of sporulation, and complete the development

115 process (11).

116 Most cultured Myxococcota, henceforth referred to as "model Myxococcota", are aerobic

117 soil dwellers, known to inhabit the top layers of agricultural, forest, and even desert soils (14).

118 This strong niche preference pattern attests to the contribution of their unique capacities to their

119 success in soil ecosystems. The dual saprophytic/predatory capacities allow Myxococcota to

120 utilize live microbial cells as well as microbial, floral, and faunal detritus as food sources (14).

121 Their gliding motility allows them not only to get in close proximity with their prey, but also to

122 access their insoluble substrates in soils (14). Their social behavior allows sharing resources

123 (especially exoenzymes), enabling a more efficient process in which higher enzymatic activity is

124 achieved when compared to individual cells (14). Fruiting bodies formation guarantee long term

125 survival under adverse and highly fluctuating conditions in soil, as well as faster recovery and

126 propagation under more favorable circumstances. 
However, while Myxococcota appears to be most successful and prevalent in soils,

128 members of this phylum have also been isolated from non-soil habitats (e.g. Nannocystaceae and

129 Haliangiaceae from aerobic marine sediments $(15,16)$, and the facultative anaerobic

130 Anaeromyxobacter from contaminated soils and sediments (17)). Further, multiple amplicon-

131 based diversity surveys have identified Myxococcota-affiliated sequences in non-soil habitats,

132 many of which represent anoxic/ hypoxic settings (18-24). Recently, the implementation of

133 genome-resolved metagenomic approaches has resulted in the recovery of Myxococcota

134 genomes from a wide range of non-soil habitats, almost invariably constituting a minor fraction

135 of the population (25-30). Interestingly, many of these yet-uncultured lineages identified using

136 16S rRNA gene amplicon or metagenomic surveys appear to represent distinct novel, yet-

137 uncultured lineages within the Myxococcota.

138 Given these observed strong niche adaptation patterns, as well as the predicted

139 correlation between Myxococcota predation and cellular differentiation capacities, and

140 successful propagation in soil, we hypothesized that novel, yet-uncultured Myxococota

141 recovered from anaerobic non-soil habitats will display distinct metabolic, physiological, and

142 lifestyle capacities when compared to their soil counterparts. Here, we analyzed multiple

143 genomes representing two novel Myxococcota lineages recovered from the completely anoxic,

144 sulfide-laden (8-10 mM) source sediment in Zodletone spring, an anaerobic sulfide-and sulfur-

145 rich spring in Oklahoma. We investigated the metabolic capacities, physiological preferences,

146 structural features, and potential social behavior of these lineages, and compared their predicted

147 capacities to model social aerobic Myxococcota. Our results suggest that non-soil Myxococcota

148 possess severely curtailed pathways for the typical social behavior of soil Myxococcota,

149 potentially utilize fermentation and/or sulfate-reduction for energy generation as opposed to 
150 aerobic respiration, and show preferences to polysaccharide and sugars, rather than proteins and

151 amino acids as carbon and energy sources. We argue that such differences provide important

152 clues to the evolution of social behavior in the Myxococcota in light of our understanding of the

153 history of soil formation and oxygen accumulation in the atmosphere. 
156 Site description and geochemistry. Zodletone spring is located in the Anadarko Basin of

157 western Oklahoma $\left(\mathrm{N} 34.99562^{\circ} \mathrm{W} 98.68895^{\circ}\right)$. The site geochemistry has been previously

158 described in detail (31-33). Briefly, at the spring source, sulfide and gaseous hydrocarbon-

159 saturated waters are slowly $(8 \mathrm{~L} / \mathrm{min})$ ejected, along with sediments that deposit at the source of

160 the spring. High $(8-10 \mathrm{mM})$ sulfide concentrations maintain complete anoxic conditions (oxygen

161 levels $<0.1 \mu \mathrm{M}$ ) in the spring sediments. Oxygen concentrations in the $50 \mathrm{~cm}$ water column

162 overlaying the sediments vary from $2-4 \mu \mathrm{M}$ at the $2 \mathrm{~mm}$ above the source to complete oxygen

163 exposure on the top of the water column (31).

164 Sampling and nucleic acid extraction. The sampling and DNA extraction process have been

165 previously described in detail $(34,35)$. Briefly, ten different sediment samples ( $\approx 50$ grams each)

166 were collected at 5-cm depth, as well as from the standing overlaid water in sterile containers.

167 DNA was extracted from 0.5 grams of source sediments from each replicate sample. For water

168 samples, 10L of water was filtered on $0.2 \mu \mathrm{m}$ sterile filters, and DNA was directly extracted

169 from filters. Extraction was conducted using the DNeasy PowerSoil kit (Qiagen, Valencia, CA,

170 USA) according to manufacturer protocols.

171 Metagenome sequencing, assembly, and binning. All extractions from sediment or water

172 samples were pooled, and the pooled DNA was used for the preparation of sequencing libraries

173 using the Nextera XT DNA library prep kit (Illumina, San Diego, CA, USA) as per

174 manufacturer's instructions. DNA sequencing was conducted using two lanes on the Illumina

175 HiSeq 2500 platform and 150-bp pair-end technology for each of the water and sediment

176 samples using the services of a commercial provider (Novogene, Beijing, China). Metagenomic

177 sequencing of the sediments and water samples yielded $281 \mathrm{Gbp}$ and $323 \mathrm{Gbp}$ of raw data, 
178 respectively. Reads were assessed for quality using FastQC followed by quality filtering and

179 trimming using Trimmomatic v0.38 (36). High quality reads were assembled into contigs using

180 MegaHit (v.1.1.3) (37) with minimum Kmer of 27, maximum kmer of 127, Kmer step of 10, and

181 minimum contig length of $1000 \mathrm{bp}$. Bowtie 2 was used to calculate the percentage of reads that

182 assembled into contigs and sequencing coverage for each contig. Contigs $>1 \mathrm{Kbp}$ were binned

183 into draft metagenome-assembled genomes (MAGs) using Metabat (38) and MaxBin2 (39),

184 followed by selection of the highest quality bins using DasTool (40). CheckM (41) was used for

185 estimation of genome completeness, strain heterogeneity, and contamination by employing the

186 lineage-specific workflow (lineage_wf flag). Quality designation of draft genomes was based on

187 the criteria set forth by MIMAGs (42).

188 Genomes classification. Taxonomic classifications followed the Genome Taxonomy Database

189 (GTDB) release r95 (43), and were carried out using the classify_workflow in GTDB-Tk

190 (v1.3.0) (44). Phylogenomic analysis utilized the concatenated alignment of a set of 120 single-

191 copy bacterial genes (43) generated by the GTDB-Tk. Maximum-likelihood phylogenomic tree

192 was constructed in RaxML using the PROTGAMMABLOSUM62 model and default parameters

193 (45) and members of the Bdellovibrionota as an outgroup. To further assign genomes to putative

194 families and genera, average amino acid identity (AAI), and shared gene content (SGC) were

195 calculated using the AAI calculator [http://enve-omics.ce.gatech.edu/]. The arbitrary AAI cutoffs

196 used were 49\%, 52\%, 56\%, and 68\% for class, order, family, and genus, respectively $(46,47)$.

197 Further, Relative Evolutionary Divergence (RED) values, based on placement in the GTDB

198 backbone tree (available at https://data.gtdb.ecogenomic.org/releases/release95/95.0/), were used

199 to confirm the novelty of lineages to which the genomes are assigned. Values between 0.62 and

$200 \quad 0.46$ are indicative of a novel order, and values between 0.62 and 0.77 of a novel family. 
Annotation and genomic analysis. Protein-coding genes were predicted using Prodigal (48).

GhostKOALA (49) was used for the annotation of every predicted open reading frame in bins visualization in KEGG mapper (50). In addition, all genomes were queried with custom-built profiles, a representative protein was queried against the KEGG genes database using Blastp, and

207 hits with e-values $<1 \mathrm{e}^{-80}$ were downloaded, aligned, and used to construct an HMM profiles using the hmmbuild function of HMMer (v 3.1b2) (51). Hydrogenases HMM profiles were built

209 using alignments downloaded from the Hydrogenase Database (HydDB) (52). The hmmscan

210 function of HMMer (51) was used with the constructed profiles and a thresholding option of -T

211100 to scan the protein-coding genes for possible hits. Further confirmation was achieved

212 through phylogenetic assessment and tree building procedures. The 5S, 16S, and 23S rRNA

213 sequences were identified using Barrnap 0.9 (https://github.com/tseemann/barrnap). tRNA

214 sequences were identified using tRNAscan-SE (v 2.0.6, May 2020) [82]. Genomes were mined

215 for CRISPR and Cas proteins using the CRISPR/CasFinder [83]. Proteases, peptidases, and

216 protease inhibitors were identified using Blastp against the MEROPS database (53), while

217 carbohydrate active enzymes (CAZymes) were identified by searching all ORFs from all

218 genomes against the dbCAN hidden Markov models V9 (54) (downloaded from the dbCAN web

219 server in September 2020). AntiSMASH 3.0 (55) was used with default parameters to predict

220 biosynthetic gene clusters in the genomes. Metabolic reconstruction of reference Myxococcota

221 type species genomes was obtained from the KEGG genomes database

222 (https://www.genome.jp/kegg/genome/) and used for comparative genomics to Zodletone

223 Myxococcota genomes. 
224 Phylogenetic analysis of dissimilatory sulfite reductase DsrAB. Predicted dissimilatory sulfite

225 reductase subunits $\mathrm{A}$ and B were compared to reference sequences for phylogenetic placement

226 by first aligning to corresponding subunits from sulfate-reducing taxa using Mafft (56). DsrA

227 and DsrB alignments were concatenated in Mega X (57), and used to construct maximum-

228 likelihood phylogenetic trees using FastTree (v 2.1.10) (58).

229 Machine learning approaches. Genomes of type species of cultured social (i.e. experimentally

230 verified to involve in predation and observed to undergo cellular differentiation) Myxococcota

231 lineages $(n=24)$ and all cultured non-social Myxococcota lineages $(n=13)$ were downloaded from

232 GenBank (June 2021). Lineages were assigned their "social” status using prior culture-based

233 observations $(15-17,59)$. Genomes were annotated with KO numbers using GhostKOALA (49)

234 using default parameters, and gene counts were assembled into a matrix. Informative KOs

$235(\mathrm{n}=634)$ were selected using indicator analysis, with the R package indicspecies (60) using the

236 multipattern function, and used to build a predictive model. Data was then centered, scaled, and

237 Box-Cox transformed using the R package caret $\{$ https://topepo.github.io/caret/ $\}$. Random forest

238 classification training was performed in Python3 with the ensemble method of scikit-learn (v

239 0.24.1) (61). The data was randomly divided, with $75 \%$ of the data selected to serve as the

240 training set and the remaining $25 \%$ reserved for model verification. Model training was

241 performed with default parameters and 1000 estimators. The model successfully predicted the

242 social behavior (with $100 \%$ accuracy) in the $25 \%$ data subset reserved for model verification.

243 Social abilities of novel Myxococcota lineages were then predicted using the constructed model.

244 Matthew's Correlation Coefficient (62) was used to quantify classification accuracy. Including

245 only pure cultures genomes' in our model with experimentally verified social behavior ensured

246 that the model was accurately trained on possession of social behavior rather than arbitrary 
bioRxiv preprint doi: https://doi.org/10.1101/2021.07.06.451402; this version posted July 7, 2021. The copyright holder for this preprint (which was not certified by peer review) is the author/funder, who has granted bioRxiv a license to display the preprint in perpetuity. It is made available under aCC-BY-ND 4.0 International license.

247 genomic artifacts due to phylogenetic relatedness.

248 Sequence and MAG accessions. The individual assembled Myxococcota MAGs analyzed in

249 this study have been deposited at DDBJ/ENA/GenBank under the accessions

250 JAFGVO000000000, JAFGQN000000000, JAFGWT000000000, JAFGTB000000000,

$251 \quad$ JAFGXQ000000000, and JAFGIB000000000. 


\section{Results}

253 Novel Myxococcota in Zodletone spring sediments. Six genomes were recovered from the

254 anoxic black sediment sources (3 MAGs) and the water column (3 MAGs) of Zodletone spring,

255 with estimated completion and contamination percentages ranging between $89.08-96.01 \%$ and

256 1.94-3.87\%, respectively. Phylogenomic analysis (Fig 1), as well as AAI and RED values (Table

257 1) placed these genomes into one novel order (order JAFGXQ01; $n=5$ ), and one novel family

258 (family JAFGIB01, order Polyangiales; $\mathrm{n}=1$ ) within the class Polyangia. Intra-order AAI values

259 assigned the five genomes in novel order JAFGXQ01 into two families (novel families

260 JAFGVO01, JAFGXQ01), and three genera (novel genera JAFGVO01, JAFGQN01,

261 JAFGXQ01). Names were assigned based on the assembly accession number of the most

262 complete genome within each lineage (Tables 1 and S1).

263 Comparative genomic analysis between Zodletone Myxococcota and model Myxococcota.

264 Comparative genomic analysis between Zodletone Myxococcota MAGs and genomes of all

265 described type species in the phylum Myxococcota $(n=27)$ was conducted. These genomes

266 belong to classes Myxococcia $(n=12)$, Polyangia $(n=12)$, and Bradymonadia $(n=3)$, and 20 of

267 which exhibit the distinct social behavior of the Myxococcota $(5-9,11-13,15-17,59)$. We

268 utilized only genomes from type species to ensure the availability of experimental data regarding

269 various aspects of their lifestyle. Compared to model Myxococcota genomes (i.e. those shown to

270 exhibit predation behavior and to form fruiting bodies, $n=20$ ); Zodletone genomes were

271 significantly smaller $(6.15 \pm 1.28 \mathrm{Mb}$ versus $11.44 \pm 2.52 \mathrm{Mb})$, with a lower gene count

272 (5129 \pm 1005 versus $9461 \pm 1611)$ and GC content $(49.53 \pm 5.67$ versus $69.68 \pm 1.74)$ (Student t-test

273 p-value <0.00001) (Figure 2). Further, multiple additional differences were observed in gene

274 families previously implicated in mediating Myxococcota social lifestyle between Zodletone 
275 MAGs and genomes of social Myxococcota. Extracellular proteolytic enzymes are crucial 276 components of the predatory machinery in Myxococcota, aiding in degrading prey-released

277 proteins and/or inducing prey lysis (6). Zodletone genomes encoded a significantly lower 278 number of proteases/peptidases when compared to model Myxococcota (58 \pm 3.4 versus 130

$279 \pm 17$ ) (Figure 2, Table S2). Of note is the absence of representatives of MEROPS Family M15

280 (peptidoglycan endopeptidases) specifically implicated in prey cell lysis (Table S2). Further,

281 model Myxococcota also secrete a plethora of secondary metabolites such as pigments,

282 siderophores, bacteriocins, and antibiotics that attack and lyse their prey (6). Zodletone

283 Myxococcota genomes encoded a significantly lower number of biosynthetic gene clusters

284 (BGCs, 8 \pm 3 ), mostly belonging to the NRPS_PKS type. By comparison, model Myxococcota

285 encoded a larger number of BGCs $(38 \pm 16)$, belonging to a wider range (NRPS, PKS, terpenes,

286 siderophores, and phenazines) of BGC classes. (Figure 2, Table S3).

287 Predation in model soil Myxococcota is also associated with secretion of extracellular or

288 outer membrane CAZymes for targeting prey cell walls. While the overall numbers of CAZymes

289 encoded in Zodletone genomes were not significantly different from those encountered in model

290 soil Myxococcota genomes (Figure 2), the CAZyome families were significantly different

291 between the two groups (Table S4). Specifically, model Myxococcota genomes were enriched in

292 two GH families: GH23 (peptidoglycan lyases, consistent with their ability to target prey cell

293 walls), and GH13 amylases (Student t-test p-value <0.02). Instead, Zodletone genomes were

294 significantly (Student t-test p-value <0.02) enriched in GH and PL families targeting

295 polysaccharide degradation, e.g. GH12, GH5, GH45, GH8, GH9 endoglucanases and

296 cellobiohydrolases for cellulose degradation; GH10, GH11 xylanases for hemicellulose 
backbone degradation, and GH43 and GH54 xylosidases for hemicellulose side chain sugar removal; and PL1 and PL11 pectin/pectate/rhamnogalacturonan lyases for pectin degradation. expanded arsenal of transcriptional factors. These include signal transduction one-component systems (OCS) (with a sensory domain and a response effector domain present in the same gene) and two-component systems (TCS) (with a sensor histidine kinase (HK), a partner response regulator (RR), and occasionally a phosphotransfer protein (PP)), as well as other transcriptional factors (TFs) including transcriptional regulators (TRs), and alternative sigma factors (SFs)"(63).

56 TF genes. In contrast, Zodletone Myxococcota genomes encoded significantly lower OCSs,

307 TCSs, and TFs $(65 \pm 14,198 \pm 58$, and 69 \pm 18 , respectively) (Student t-test $\mathrm{p}<0.05)$ (Figure 2,

308 Table S5). This pattern of curtailed transcription factor repertoire in Zodletone genomes was 309 pronounced in OCS and TCS systems (Figure 2), specifically OCS families AraC, ArsR, GntR, 310 LysR, MarR, TetR, and Xre, and TCS-RR belonging to the families CheY, NarL, OmpR, and 311 FrzZ (Table S5) (Student t-test p-value <0.05).

\section{Comparative genomics analysis of predation and cellular differentiation genes/pathways in}

313 the Myxococcota. We assessed the distribution patterns of pathways implicated in Myxococcota

314 social behavior in Zodletone Myxococcota and compared them to Myxococcus xanthus, the

315 model myxobacterium extensively studied for its social behavior, as well as to

316 Anaeromyxobacter dehalogenes, Vulgatibacter incomptus, and Labilithrix luteola. These three

317 isolates share many genomic features with social Myxococcota (large genome size, high \%GC,

318 large number of genes), but lack predation and fruiting body formation capacities $(64,65)$.

319 Thirteen pathways were examined: four gene regulatory networks governing sporulation, 
aggregation, and fruiting body formation; exopolysaccharide production genes; two extracellular

321 signals production gene clusters (A-signal and C-signal); aggregation, sporulation, and fruiting

322 body formation genes; chemosensory pathways; developmental timers; two motility gene

323 clusters (A-motility and S-motility); and outer membrane exchange genes (Figure 3, Tables 2, S.

324 text and S6). Detailed analysis of the distribution patterns of genes in these pathways, as well as

325 a background on their known functions are presented in the supplementary document (S. text).

326 Collectively, our analysis clearly demonstrates that social behavior pathways were severely

327 curtailed in Zodletone Myxococcota genomes (Tables 2, S. text, S6), where homologues of genes

328 specific for the model Myxococcota social lifestyle (e.g. sporulation, extracellular signal

329 production, motility, outer membrane exchange) were missing from Zodletone genomes.

330 Specifically, the most notable deficiencies are the absence of homologues for extracellular

331 signals production that control early events in aggregation, the absence of homologues for the

332 two transcription factors FruA and MrpC that work cooperatively to control the start of

333 sporulation (66-68), the absence of homologues for sporulation specific genes $(11,66,68-70)$,

334 and A motility-specific genes, and the absence of homologues for the outer membrane exchange

335 receptor TraA that recognizes kin and allow membrane fusion (12) in Zodletone Myxococcota

336 genomes or genomes of Anaeromyxobacter dehalogenes. Labilithrix luteola, and Vulgatibacter

337 incomptus known from pure culture work not to aggregate into mounds, form fruiting bodies, or

338 sporulate. Further, for the pathways with homologues identified, the majority of genes encoded

339 proteins with domain similarities to known transcriptional response regulators or serine/

340 threonine kinases, peptidase domains, guanylate cyclase domains, chemotaxis-associated

341 domains, or type IV pili, all of which are widely distributed in bacteria.

\section{Machine learning approaches suggest absence of social behavior in Zodletone}


343 Myxococcota. It is important to note that most of the physiological, mutational, and

344 transcriptomic studies on soil Myxococcota were conducted on the model organism M. xanthus,

345 (Class Myxococcia), a relatively distant relative of Zodletone Myxococcota (Class Polyangia).

346 Further, while genes for exopolysaccharide production, adventurous motility, extracellular signal

347 production, and sporulation are highly specific, a large proportion of the gene regulatory network

348 and developmental timing proteins governing aggregation, sporulation and fruiting body

349 formation are homologues to signal transduction proteins involved in various cellular processes

350 in a wide swaths of lineages, and are hence universally distributed within the bacterial world.

351 Similarly, chemosensory network proteins in Myxococcota are homologues to a wide range of

352 chemotaxis proteins. Indeed, in the genomes of the non-social Anaeromyxobacter dehalogenes,

353 Labilithrix luteola, and Vulgatibacter incomptus, homologues for the highly specific

354 extracellular signal production, and sporulation genes were not identified, but homologues for

355 chemosensory networks and gene regulatory networks were found, attesting to the above caveats 356 with the approach.

357 Therefore, as a complementary approach, we employed a machine learning technique to

358 predict social behavior potential in Zodletone Myxococcota. The approach depends on first

359 identifying, from the initial set of all genes in the genomes, a group of genes with assigned KO

360 numbers in the genomes of known social Myxococcota that are absent from genomes of known

361 non-social Myxococcota. These candidate genes were then used for model training using a

362 Random Forest algorithm, and the constructed model was employed to predict the social

363 behavior based on the genomic content of Zodletone Myxococcota genomes. The occurrence

364 pattern of the list of 634 KOs (Dataset 1) selected for model training predicted non-social

365 behavior for Zodletone Myxococcota lineages with a Matthew's correlation coefficient of +1 , 
confirming the patterns observed with the comparative genomics approach detailed above.

367 Structural features and metabolic capacities. Structurally, Zodletone Myxococcota MAGs

368 encoded determinants of Gram-negative cell walls (LPS biosynthesis and G- peptidoglycan

369 structure), motility (flagellar assembly and type IV pili), pigmentation (carotenoid biosynthesis),

370 chemotaxis, and rod-shape (MreBCD and RodA). The genomes also encoded Type III (partial)

371 and type VI secretion systems. Such characteristics are similar to those displayed by vegetative

372 cells of cultured Myxococcota (Figure 4a, Table S7).

Genomic analysis predicted key differences in anabolic capacities between Zodletone

374 Myxococcota and cultured Myxococcota. Zodletone MAGs did not encode the capacity for

375 glycogen or trehalose biosynthesis, both of which are biosynthesized and used as storage

376 molecules by cultured Myxococcota, and shown to be essential for sporulation (71).

377 Additionally, evidences for a glyoxylate shunt were missing from Zodletone MAGs. The

378 glyoxylate shunt is employed by cultured Myxococcota to bypass $\mathrm{CO}_{2}$ loss and NADH

379 production during the TCA cycle and drive the metabolism towards oxaloacetate in preparation

380 for gluconeogenesis (72). Further, key differences in levels of amino acids auxotrophy were

381 predicted, where Zodletone Myxococcota MAGs encoded capacities for biosynthesis of almost

382 all amino acids, compared to the observed auxotrophy for branched chain amino acids (in 9 type

383 species) and aromatic amino acids (in 5 type species) in cultured Myxococcota $(73,74)$. Such

384 pattern reflects the dependence of cultured Myxococcota on proteins and amino acids as

385 substrates (and hence their ready availability for biosynthetic purposes) as opposed to the lack of

386 such capacity in Zodletone genomes, necessitating amino acid biosynthesis from metabolic

387 precursors. Finally, while cultured Myxococcota are able to incorporate sulfur from sulfate as

388 well as organic sources (e.g. taurine, alkane sulfonate, and dimethyl sulfone in 6 type species), 
and incorporate $\mathrm{N}$ from ammonia as well as organic sources (e.g. urea in 11 type species), such capacities for $\mathrm{S}$ or $\mathrm{N}$ incorporation from organic sources were not encoded in Zodletone

391 Myxococcota MAGs (Table S7). Additionally, order JAFGXQ01 genomes encoded the

392 capability to fix atmospheric nitrogen (Figure 4a, Table S7).

394 (substrate utilization patterns, respiratory capacities, electron recycling pathways, and ATP

395 generation mechanisms) between Zodletone and model Myxococcota genomes. While most

396 model Myxococcota (with the exception of Sorangium cellulosum) rely on amino acids and

397 lipids as substrates and are poor carbohydrate consumers (71), Zodletone genomes encode a

398 much lower number of amino acid degradation pathways (only 9, compared to 15 in type

399 species), consistent with their observed limited proteolytic capabilities (Table S2). Instead,

400 Zodletone Myxococcota appear to possess a more extensive carbohydrate degradation capacity

401 (Tables 3, S7, Figure 4a), with pathways enabling the degradation of nine different sugars, sugar

402 alcohols, sugar amines, and uronic acids encoded in their genomes. This is consistent with the

403 possession of a wide range of polysaccharide-degrading CAZymes, as described above (Table

404 S4). Finally, Zodletone order JAFGXQ01 genomes encoded an incomplete beta-oxidation

405 pathway for long chain fatty acid degradation (Table 3, Figure 4a), a pathway commonly

406 occurring in cultured Myxococcota to enable fatty acid consumption as the main carbon and

407 energy source.

408 All cultured Myxococcota (with the exception of the genus Anaeromyxobacter) are

409 aerobic microorganisms. In contrast, Zodletone Myxococcota genomes lack key genes for

410 aerobic respiration, specifically homologues for either complex III or alternative complex III, as

411 well as the absence of homologues for the low affinity cytochrome oxidase aa3. High affinity 
412 cytochrome bd ubiquinol oxidase is encoded in Zodletone genomes, but could possibly be

413 employed in detoxification of trace amounts of $\mathrm{O}_{2}$ present. Instead, the genomes encode genes

414 enabling the utilization of nitrite as a terminal electron acceptor via the cytochrome-linked nitrite

415 reductase NrfAH (Table 3, Figure 4a). Further, the single genome representative of novel family

416 JAFGIB01 encodes a full dissimilatory sulfate reduction machinery including 3'-

417 phosphoadenosine 5'-phosphosulfate synthase [Sat; EC:2.7.7.4 2.7.1.25] for sulfate activation to

418 APS, adenylylsulfate reductase [AprAB; EC:1.8.99.2] for adenylyl sulfate reduction to sulfite,

419 QmoABC for electron transfer, dissimilatory sulfite reductase [DsrAB; EC:1.8.99.5] and its co-

420 substrate DsrC for dissimilatory sulfite reduction to sulfide, and the sulfite reduction-associated

421 membrane complex DsrMKJOP for linking cytoplasmic sulfite reduction to energy conservation

422 (Table 3, Figure 4a). JAFGIB01 genome also encoded octaheme tetrathionate reductase (otr) and

423 thiosulfate reductase $p h A B C$, suggesting the capability to utilize tetrathionate and thiosulfate as

424 terminal electron acceptors in addition to sulfate (Figure 4a). This is the first genomic report of

425 sulfur species respiration capability in the Myxococcota, and could possibly be a reflection of the

426 sulfur and sulfide-rich Zodletone Spring environment from which the MAGs were binned.

427 Phylogenetically, JAFGIB01 DsrAB were most closely affiliated to DsrAB sequences

428 encountered in Acidobacteria genomes (Figure 4b) (34).

429 Besides respiration, additional pathways for electron disposal were identified in

430 Zodletone Myxococcota genomes. These include fermentative processes for acetate, ethanol, and

431 lactate production from pyruvate (Table 3, Figure 4a). As well, the genomes encoded a full

432 Wood Ljungdahl pathway (WLP), most probably acting as an electron sink mechanism for re-

433 oxidizing reduced ferredoxin, as previously noted in Candidatus Bipolaricaulota and

434 Desulfobacterota genomes $(35,75)$. Finally, a possible additional mechanism for ATP 
435 production in Zodletone Myxococcota is the utilization of the RNF complex for re-oxidizing

436 reduced ferredoxin at the expense of NAD, with the concomitant export of protons to the

437 periplasm, generating a proton motive force that can drive ATP production via oxidative

438 phosphorylation via the encoded F-type ATP synthase. Consistent with encoding RNF complex

439 components, the genomes also encoded elements for electron carriers recycling including the

440 cytoplasmic electron bifurcating mechanism HydABC. Analysis of Myxococcota type species

441 genomes revealed absence of RNF complex components, HydABC electron bifurcation system,

442 as well as the WLP pathway, consistent with a strictly aerobic mode of metabolism. 


\section{Discussion}

445 Our comparative genomics and machine learning analyses revealed severely curtailed

446 machineries for predation and cellular differentiation in MAGs representing a novel order and a

447 novel family of Myxococcota recovered from Zodletone spring (Figures 2, 3, Tables 2 and S6).

448 Such results are in-agreement with a recent study that predicted absence of predation potential in

449 MAGs/SAGs encompassing most of the publicly available, yet-uncultured Myxococcota (4). As

450 such, a clear delineation exists between two phylogenetically and behaviorally distinct groups

451 within the Myxococcota. The first encompasses aerobic top soil dwellers in classes Myxococcia

452 and Polyangia that are characterized by possessing a highly sophisticated machinery enabling

453 predation and cellular differentiation behaviors. Few freshwater and marine strains possessing

454 such capacities have been reported, but their presence has been attributed to air and dust

455 transport from neighboring soils $(15,16)$. Members of this group could readily be obtained in

456 pure cultures. The second group encompasses phylogenetically distinct families and orders

457 within the classes Myxococcia and Polyangia (including Zodletone MAGs), as well a few yet-

458 uncultured Myxococcota classes. These lineages are almost invariably encountered within non-

459 soil habitats (e.g. freshwater, marine, host-associated, and engineered ecosystems), and appear to

460 lack the capacity for predation and social differentiation. Most of these lineages are currently

461 uncultured, with the exception of members of the genus Anaeromyxobacter (76).

462 We argue that such patterns could provide important clues on the evolution of social

463 behavior in the Myxococcota, when considered in light of our understanding of the history of soil

464 formation and the rise of atmospheric oxygen in the atmosphere. Soil formation and transition

465 from barren crusts to current soil orders through organic matter deposition and transformation

466 has been enabled by the evolution of lichen associations, plant terrestrialization, formation of 
mycorrhizal association, and subsequent colonization by soil microfauna. All such processes are mediated by aerobic organisms (algae, fungi, plants, fauna), and hence was possible only after the accumulation of oxygen to levels comparable to current values in the atmosphere

470 (approximately 500-600 Mya (77)). The formation of soil structures as a new and organic-rich

471 habitat has certainly spurred multiple evolutionary processes for enabling terrestrial adaptation

472 within the microbial world. Various processes have been reported in multiple soil-prevalent

473 lineages, from CAZymes and BGCs acquisition in the Acidobacteria $(34,78)$, to acquisition of

474 stress tolerance, adherence, and regulatory genes in the ammonia-oxidizing archaea (79). Here, it

475 appears that the development of predation and cellular differentiation machineries has enabled

476 the Myxococcota to assume an apex predator niche and imparted them with strong survival

477 capacities in soil, respectively. Indeed, as previously noted, the ecological success of social

478 Myxococcota in soils appears to be in stark contrast to their rarity and low relative abundance of

479 non-social Myxococcota in other habitats (80).

480 Evolution of beneficial trait(s) in a single lineage of Myxococcota in soil could be

481 propagated to the broader soil Myxococcota community through intra-clade, habitat-specific

482 horizontal gene transfer (HGT), resulting in the observed checkered distribution pattern, where

483 social behavior is observed only in specific families within the classes Myxococcia and

484 Polyangia. HGT between closely related taxa is a well-established phenomenon (81) that has

485 been widely documented, e.g. in mediating the spread of antibiotic resistance in related clinical

486 strains $(82,83)$. The barrier for HGT within closely related taxa is predictably lower, given

487 expected similarity in codon usage pattern, GC content, restriction enzyme machinery, and

488 overall genome architecture between donor and recipient strains. Similarly, physical proximity in

489 the same habitat is seen as a facilitator of genetic exchange through HGT (84-86). 
In conclusion, our results strongly indicate that anaerobic Myxococcota do not posses the

491 capacity for typical social behavior, and display distinct structural, anabolic, and catabolic

492 differences when compared to model aerobic Myxococcota. We document their dependence on

493 fermentation and/or nitrite and sulfate-reduction for energy generation, as well as their

494 preference for polysaccharide metabolism over protein, amino acids, and lipid metabolism. We

495 further propose that such differences strongly underscore the importance of niche differentiation

496 in shaping the evolutionary trajectory of the Myxococcota, and suggest soil formation as a strong

497 driver for developing social behavior in this lineage.

498

499 Acknowledgments. We thank Dr. David W. Waite at the Australian Centre for Ecogenomics,

500 School of Chemistry and Molecular Biosciences, University of Queensland, for helpful

501 discussions regarding utilization of machine learning approaches for trait prediction. This work

502 was supported by NSF grant 2016423 to NHY and MSE. 


\section{References}

504 1. Shimkets LJ, Dworkin M, Reichenbach H. The Myxobacteria. In: Dworkin M, Falkow S,

505 Rosenberg E, Schleifer K-H, Stackebrandt E, editors. The Prokaryotes: Volume 7:

506 Proteobacteria: Delta, Epsilon Subclass. New York, NY: Springer New York; 2006. p. 31-115.

507 2. Shimkets L, Woese CR. A phylogenetic analysis of the myxobacteria: basis for their

508 classification. Proc Natl Acad Sci. 1992;89(20):9459.

509 3. Spröer C, Reichenbach H, Stackebrandt E. The correlation between morphological and

510 phylogenetic classification of myxobacteria. Int J Syst Evol Microbiol. 1999;49(3):1255-62.

511 4. Waite DW, Chuvochina M, Pelikan C, Parks DH, Yilmaz P, Wagner M, et al. Proposal to

512 reclassify the proteobacterial classes Deltaproteobacteria and Oligoflexia, and the phylum

513 Thermodesulfobacteria into four phyla reflecting major functional capabilities. Int J Syst Evol

514 Microbiol. 2020;70(11):5972-6016.

515 5. Cao P, Dey A, Vassallo CN, Wall D. How Myxobacteria Cooperate. J Mol Biol.

$516 \quad 2015 ; 427(23): 3709-21$

517 6. Thiery S, Kaimer C. The predation strategy of Myxococcus xanthus. Front Microbiol.

$518 \quad 2020 ; 11: 2$

519 7. Berleman JE, Kirby JR. Deciphering the hunting strategy of a bacterial wolfpack. FEMS

$520 \quad$ Microbiol Rev. 2009;33(5):942-57.

521 8. Marshall RC, Whitworth DE. Is "Wolf-Pack" predation by antimicrobial bacteria

522 cooperative? Cell behaviour and predatory mechanisms indicate profound selfishness, even when

523 working alongside kin. Bioessays. 2019;41(4):e1800247.

524 9. Muñoz-Dorado J, Marcos-Torres FJ, García-Bravo E, Moraleda-Muñoz A, Pérez J.

525 Myxobacteria: moving, killing, feeding, and surviving together. Front Microbiol. 2016;7(781). 
527 Cuadrado AB, Schrader JM, et al. Transcriptome dynamics of the Myxococcus xanthus

528 multicellular developmental program. Elife. 2019;8.

529 11. Kroos L. Highly signal-responsive gene regulatory network governing Myxococcus

530 development. Trends Genet. 2017;33(1):3-15.

531 12. Sah GP, Wall D. Kin recognition and outer membrane exchange (OME) in myxobacteria.

532 Curr Opin Microbiol. 2020;56:81-8.

533 13. Zusman DR, Scott AE, Yang Z, Kirby JR. Chemosensory pathways, motility and

534 development in Myxococcus xanthus. Nat Rev Microbiol. 2007;5(11):862-72.

535 14. Reichenbach H. The ecology of the myxobacteria. Environ Microbiol. 1999;1(1):15-21.

536 15. Garcia R, Müller R. The Family Nannocystaceae. In: Rosenberg E, DeLong EF, Lory S,

537 Stackebrandt E, Thompson F, editors. The Prokaryotes: Deltaproteobacteria and

538 Epsilonproteobacteria. Berlin, Heidelberg: Springer Berlin Heidelberg; 2014. p. 213-29.

539 16. Garcia R, Müller R. The Family Haliangiaceae. In: Rosenberg E, DeLong EF, Lory S,

540 Stackebrandt E, Thompson F, editors. The Prokaryotes: Deltaproteobacteria and

541 Epsilonproteobacteria. Berlin, Heidelberg: Springer Berlin Heidelberg; 2014. p. 173-81.

542 17. dos Santos DFK, Kyaw CM, De Campos TA, Miller RNG, Noronha EF, Bustamante MMdC,

543 et al. The Family Cystobacteraceae. In: Rosenberg E, DeLong EF, Lory S, Stackebrandt E,

544 Thompson F, editors. The Prokaryotes: Deltaproteobacteria and Epsilonproteobacteria. Berlin,

545 Heidelberg: Springer Berlin Heidelberg; 2014. p. 19-40.

546 18. Ji Y, Angel R, Klose M, Claus P, Marotta H, Pinho L, et al. Structure and function of

547 methanogenic microbial communities in sediments of Amazonian lakes with different water

548 types. Environ Microbiol. 2016;18(12):5082-100. 
550 phylogenetic analysis of moderately thermophilic myxobacteria from hot springs in Japan.

551 Microbes Environ. 2006;21(3):189-99.

552 20. Tian F, Yu Y, Chen B, Li H, Yao Y-F, Guo X-K. Bacterial, archaeal and eukaryotic diversity

553 in Arctic sediment as revealed by 16S rRNA and 18S rRNA gene clone libraries analysis. Polar

554 Biol. 2009;32(1):93-103.

555 21. Kandel PP, Pasternak Z, van Rijn J, Nahum O, Jurkevitch E. Abundance, diversity and

556 seasonal dynamics of predatory bacteria in aquaculture zero discharge systems. FEMS Microbiol

557 Ecol. 2014;89(1):149-61.

558 22. Li SG, Zhou XW, Li PF, Han K, Li W, Li ZF, et al. The existence and diversity of

559 myxobacteria in lake mud - a previously unexplored myxobacteria habitat. Environ Microbiol

$560 \quad$ Rep. 2012;4(6):587-95.

561 23. Kou W, Zhang J, Lu X, Ma Y, Mou X, Wu L. Identification of bacterial communities in

562 sediments of Poyang Lake, the largest freshwater lake in China. Springerplus. 2016;5:401.

563 24. Mohr KI. Diversity of Myxobacteria-we only see the tip of the iceberg. Microorganisms.

$564 \quad 2018 ; 6(3): 84$

565 25. Almeida A, Nayfach S, Boland M, Strozzi F, Beracochea M, Shi ZJ, et al. A unified catalog 566 of 204,938 reference genomes from the human gut microbiome. Nat Biotechnol. 2021;39(1):105-

56714.

568 26. Royo-Llonch M, Sánchez P, Ruiz-González C, Salazar G, Pedrós-Alió C, Labadie K, et al.

569 Ecogenomics of key prokaryotes in the arctic ocean. bioRxiv. 2020:2020.06.19.156794. 
571 interactions of uncultured organisms shaped by eco-thermodynamics in methanogenic

572 bioprocesses. Microbiome. 2020;8(1):111-.

573 28. Ye L, Mei R, Liu W-T, Ren H, Zhang X-X. Machine learning-aided analyses of thousands of

574 draft genomes reveal specific features of activated sludge processes. Microbiome. 2020;8(1):16.

575 29. Robbins SJ, Song W, Engelberts JP, Glasl B, Slaby BM, Boyd J, et al. A genomic view of

576 the microbiome of coral reef demosponges. ISME J. 2021;15(6):1641-54.

577 30. Jégousse C, Vannier P, Groben R, Glöckner FO, Marteinsson V. A total of 219 metagenome-

578 assembled genomes of microorganisms from Icelandic marine waters. PeerJ. 2021;9:e11112.

579 31. Buhring SI, Sievert SM, Jonkers HM, Ertefai T, Elshahed MS, Krumholz LR, et al. Insights

580 into chemotaxonomic composition and carbon cycling of phototrophic communities in an

581 artesian sulfur-rich spring (Zodletone, Oklahoma, USA), a possible analog for ancient microbial

582 mat systems. Geobiology. 2011;9:166-79.

583 32. Senko JM, Campbell BS, Henricksen JR, Elshahed MS, Dewers TA, Krumholz LR. Barite

584 deposition mediated by photootrophic sulfide-oxidizing bacteria. Geochim Cosmochim Acta.

$585 \quad 2004 ; 68: 773-80$.

586 33. Spain AM, Najar FZ, Krumholz LR, Elshahed MS. Metatranscriptomic analysis of a high-

587 sulfide aquatic spring reveals insights into sulfur cycling and unexpected aerobic metabolism.

588 Peer J. 2015;3:e1259.

589 34. Yadav A, Borrelli JC, Elshahed MS, Youssef NH. Genomic analysis of family UBA6911

590 (Group 18 Acidobacteria) expands the metabolic capacities of the phylum and highlights

591 adaptations to terrestrial habitats. bioRxiv. 2021:2021.04.09.439258. 
593 characterization of three novel Desulfobacterota classes expand the metabolic and phylogenetic

594 diversity of the phylum. Environ Microbiol. 2021:_doi: 10.1111/1462-2920.15614.

595 36. Bolger AM, Lohse M, Usadel B. Trimmomatic: a flexible trimmer for Illumina sequence 596 data. Bioinformatics. 2014;30(15):2114-20.

597 37. D. Li CML, R. Luo, K. Sadakane, T.W. Lam,. MEGAHIT: an ultra-fast single-node solution 598 for large and complex metagenomics assembly via succinct de Bruijn graph. Bioinformatics.

599 2015: 1674-6.

600 38. Kang DD, Li F, Kirton E, Thomas A, Egan R, An H, et al. MetaBAT 2: an adaptive binning

601 algorithm for robust and efficient genome reconstruction from metagenome assemblies. PeerJ.

602 2019;7:e7359-e.

603 39. Wu YW, Simmons BA, Singer SW. MaxBin 2.0: an automated binning algorithm to recover 604 genomes from multiple metagenomic datasets. Bioinformatics. 2016;32:605-7.

605 40. Sieber CMK, Probst AJ, Sharrar A, Thomas BC, Hess M, Tringe SG, et al. Recovery of 606 genomes from metagenomes via a dereplication, aggregation and scoring strategy. Nat

607 Microbiol. 2018;3(7):836-43.

608 41. D.H. Parks MI, C.T. Skennerton, P. Hugenholtz, G.W. Tyson. CheckM: assessing the quality

609 of microbial genomes recovered from isolates, single cells, and metagenomes. Genome Res

$610 \quad 2015 ; 25: 1043-55$

611 42. Bowers RM, Kyrpides NC, Stepanauskas R, Harmon-Smith M, Doud D, Reddy TBK, et al.

612 Minimum information about a single amplified genome (MISAG) and a metagenome-assembled 613 genome (MIMAG) of bacteria and archaea. Nat Biotechnol. 2017;35(8):725-31. 
614 43. Parks DH, Chuvochina M, Chaumeil P-A, Rinke C, Mussig AJ, Hugenholtz P. A complete

615 domain-to-species taxonomy for Bacteria and Archaea. Nat Biotechnol. 2020;38(9):1079-86.

616 44. Chaumeil P-A, Mussig AJ, Hugenholtz P, Parks DH. GTDB-Tk: a toolkit to classify

617 genomes with the Genome Taxonomy Database. Bioinformatics. 2019;36(6):1925-7.

618 45. Kozlov AM, Darriba D, Flouri T, Morel B, Stamatakis A. RAxML-NG: a fast, scalable and

619 user-friendly tool for maximum likelihood phylogenetic inference. Bioinformatics.

$620 \quad 2019 ; 35(21): 4453-5$.

621 46. Konstantinidis KT, Rosselló-Móra R, Amann R. Uncultivated microbes in need of their own

622 taxonomy. ISME J. 2017;11(11):2399-406.

623 47. D.H. Parks CR, M. Chuvochina, P.A. Chaumeil, B.J. Woodcroft, P.N. Evans, P. Hugenholtz,

624 G.W. Tyson. Recovery of nearly 8,000 metagenome-assembled genomes substantially expands

625 the tree of life. Nat Microbiol. 2017;2:1533-42.

626 48. Hyatt D, Chen G-L, Locascio PF, Land ML, Larimer FW, Hauser LJ. Prodigal: prokaryotic

627 gene recognition and translation initiation site identification BMC Bioinformatics. 2010;11:119.

628 49. Kanehisa M, Sato Y, Morishima K. BlastKOALA and GhostKOALA: KEGG tools for

629 functional characterization of genome and metagenome sequences. J Mol Biol. 2016;428(4):726-

63031.

631 50. Kanehisa M, Sato Y. KEGG Mapper for inferring cellular functions from protein sequences.

632 Prot Sci. 2020;29(1):28-35.

633 51. Mistry J, Finn RD, Eddy SR, Bateman A, Punta M. Challenges in homology search:

634 HMMER3 and convergent evolution of coiled-coil regions. Nucleic Acids Res.

$635 \quad 2013 ; 41(12): \mathrm{e} 121$. 
52. Søndergaard D, Pedersen CN, Greening C. HydDB: A web tool for hydrogenase

637 classification and analysis. Sci Rep. 2016;6:34212.

638 53. Rawlings ND, Barrett AJ, Thomas PD, Huang X, Bateman A, Finn RD. The MEROPS

639 database of proteolytic enzymes, their substrates and inhibitors in 2017 and a comparison with

640 peptidases in the PANTHER database. Nucleic Acids Res. 2017;46(D1):D624-D32.

641 54. Huang L, Zhang H, Wu P, Entwistle S, Li X, Yohe T, et al. dbCAN-seq: a database of

642 carbohydrate-active enzyme (CAZyme) sequence and annotation. Nucleic Acids Res.

643 2017;46(D1):D516-D21.

644 55. Medema MH, Blin K, Cimermancic P, de Jager V, Zakrzewski P, Fischbach MA, et al.

645 antiSMASH: rapid identification, annotation and analysis of secondary metabolite biosynthesis

646 gene clusters in bacterial and fungal genome sequences. Nucleic Acids Res. 2011;39(Web Server

647 issue):W339-W46.

648 56. Nakamura T, Yamada KD, Tomii K, Katoh K. Parallelization of MAFFT for large-scale

649 multiple sequence alignments. Bioinformatics. 2018;34(14):2490-2.

650 57. Kumar S, Stecher G, Li M, Knyaz C, Tamura K. MEGA X: Molecular Evolutionary Genetics

651 Analysis across Computing Platforms. Mol Biol Evol. 2018;35(6):1547-9.

652 58. Price MN, Dehal PS, Arkin AP. FastTree 2 - Approximately maximum-likelihood trees for

653 large alignments. PLOS ONE. 2010;5(3):e9490.

654 59. Garcia R, Müller R. The Family Myxococcaceae. In: Rosenberg E, DeLong EF, Lory S,

655 Stackebrandt E, Thompson F, editors. The Prokaryotes: Deltaproteobacteria and

656 Epsilonproteobacteria. Berlin, Heidelberg: Springer Berlin Heidelberg; 2014. p. 191-212.

657 60. De Cáceres M, Legendre P. Associations between species and groups of sites: indices and

658 statistical inference. Ecology. 2009;90(12):3566-74. 
61. Pedregosa F, Varoquaux Ge, Gramfort A, Michel V, Thirion B, Grisel O, et al. Scikit-learn: Machine Learning in Python. J Machine Learning Res. 2011;12:2825-30. score and accuracy in binary classification evaluation. BMC Genomics. 2020;21(1):6.

664 Microorganisms. 2020;8(11). dehalogenans gen. nov., sp. nov., an aryl-halorespiring facultative anaerobic myxobacterium.

667 Appl Environ Microbiol. 2002;68(2):893-900.

669 Labilithrix luteola gen. nov., sp. nov., two myxobacteria isolated from soil in Yakushima Island,

670 and the description of Vulgatibacteraceae fam. nov., Labilitrichaceae fam. nov. and

671 Anaeromyxobacteraceae fam. nov. Int J Syst Evol Microbiol. 2014;64(Pt 10):3360-8.

672 66. Mittal S, Kroos L. Combinatorial regulation by a novel arrangement of FruA and MrpC2

673 transcription factors during Myxococcus xanthus development. J Bacteriol. 2009;191(8):2753-63.

674 67. Ogawa M, Fujitani S, Mao X, Inouye S, Komano T. FruA, a putative transcription factor

675 essential for the development of Myxococcus xanthus. Mol Microbiol. 1996;22(4):757-67.

676 68. Robinson M, Son B, Kroos D, Kroos L. Transcription factor MrpC binds to promoter regions

677 of hundreds of developmentally-regulated genes in Myxococcus xanthus. BMC Genomics.

$678 \quad 2014 ; 15: 1123$.

679 69. Boysen A, Ellehauge E, Julien B, Søgaard-Andersen L. The DevT protein stimulates

680 synthesis of FruA, a signal transduction protein required for fruiting body morphogenesis in

681 Myxococcus xanthus. J Bacteriol. 2002;184(6):1540-6. 
70. Müller FD, Treuner-Lange A, Heider J, Huntley SM, Higgs PI. Global transcriptome analysis

683 of spore formation in Myxococcus xanthus reveals a locus necessary for cell differentiation.

684 BMC Genomics. 2010;11:264.

685 71. Curtis PD, Shimkets LJ. Metabolic pathways relevant to predation, signaling, and

686 development. In: Whitworth DE, editors. Myxobacteria: Multicellularity and Differentiation.

687 ASM press; 2007. p. 241-58.

688 72. Müller F-D, Treuner-Lange A, Heider J, Huntley SM, Higgs PI. Global transcriptome

689 analysis of spore formation in Myxococcus xanthus reveals a locus necessary for cell

690 differentiation. BMC Genomics. 2010;11(1):264.

691 73. Bretscher AP, Kaiser D. Nutrition of Myxococcus xanthus, a fruiting myxobacterium. J

692 Bacteriol. 1978;133(2):763-8.

693 74. Dworkin M. Nutritional requirements for vegetative growth of Myxococcus xanthus. J

694 Bacteriol. 1962;84(2):250-7.

695 75. Youssef NH, Farag IF, Rudy S, Mulliner A, Walker K, Caldwell F, et al. The Wood-

696 Ljungdahl pathway as a key component of metabolic versatility in candidate phylum

697 Bipolaricaulota (Acetothermia, OP1). Environ Microbiol Rep. 2019;11(4):538-47.

698 76. Thomas SH, Wagner RD, Arakaki AK, Skolnick J, Kirby JR, Shimkets LJ, et al. The mosaic

699 genome of Anaeromyxobacter dehalogenans strain 2CP-C suggests an aerobic common ancestor

700 to the delta-proteobacteria. PloS one. 2008;3(5):e2103-e.

701 77. Canfield DE. A new model for Proterozoic ocean chemistry. Nature. 1998;396(6710):450-3.

702 78. Eichorst SA, Trojan D, Roux S, Herbold C, Rattei T, Woebken D. Genomic insights into the

703 Acidobacteria reveal strategies for their success in terrestrial environments. Environ Microbiol.

$704 \quad$ 2018;20(3):1041-63. 
79. Abby SS, Kerou M, Schleper C, Lovley DR, Makarova K, Forterre P. Ancestral reconstructions decipher major adaptations of ammonia-oxidizing archaea upon radiation into

707 moderate terrestrial and marine environments. mBio. 2020;11(5):e02371-20.

708 80. Zhou X-w, Li S-g, Li W, Jiang D-m, Han K, Wu Z-h, et al. Myxobacterial community is a

709 predominant and highly diverse bacterial group in soil niches. Environ Microbiol Rep.

$710 \quad 2014 ; 6(1): 45-56$.

711 81. Adato O, Ninyo N, Gophna U, Snir S. Detecting horizontal gene transfer between closely

712 related taxa. PLOS Comput Biol. 2015;11(10):e1004408.

713 82. Donnenberg MS. Pathogenic strategies of enteric bacteria. Nature. 2000;406(6797):768-74.

714 83. Pallen MJ, Wren BW. Bacterial pathogenomics. Nature. 2007;449(7164):835-42.

715 84. Beiko RG, Harlow TJ, Ragan MA. Highways of gene sharing in prokaryotes. Proc Natl Acad

716 Sci USA. 2005;102(40):14332-7.

717 85. Moliner C, Fournier PE, Raoult D. Genome analysis of microorganisms living in amoebae

718 reveals a melting pot of evolution. FEMS Microbiol Rev. 2010;34(3):281-94.

719 86. Shterzer N, Mizrahi I. The animal gut as a melting pot for horizontal gene transfer. Can J

720 Microbiol. 2015;61(9):603-5. 


\section{$722 \quad$ Figure legends}

723 Figure 1. Phylogenomics of the Myxococcota including novel lineages from Zodletone spring.

724 The maximum likelihood trees were constructed in RAxML (45) using all Myxococcota

725 genomes available from GTDB r95 database based on the concatenated alignments of 120

726 housekeeping genes obtained from GTDB-Tk (44). The tree was rooted (root not shown) with

727 the two Bdellovibrionota genomes Halobacteriovorax marinus (GCF_000210915.2) and

728 Bdellovibrio bacteriovorax (GCF_000196175.1). The tree is wedged (shown as black circles at

729 the end of branches) to represent genus level taxonomy (g__ $)$, unless the number of available

730 genomes per genus is less than 5 , in which case the family level (f__ $)$, or order level (o__)

731 taxonomy is shown instead. The size of the wedge is proportional to the number of genomes.

732 Bootstrap support values based on 100 replicates are shown as triangles for nodes with $>70 \%$

733 support. Class-level taxonomy is color coded as shown in the legend. The track around the tree

734 represents the ecosystem classification of the habitat from which the genomes originated.

735 Zodletone genomes are labeled in blue bold text with their GenBank assembly accession number.

736 Figure 2. Comparative genomics of Zodletone novel Myxococcota genomes to the genomes of

73727 type species belonging to the classes Myxococcia, Polyangia, and Bradymonadia. GenBank

738 assembly accession numbers are: Anaeromyxobacter dehalogenans 2CP-1, GCF_000022145.1;

739 Haliangium ochraceum DSM 14365, GCF_000024805.1; Plesiocystis pacifica SIR-1,

740 GCF_000170895.1; Corallococcus coralloides DSM 2259, GCF_000255295.1; Cystobacter

741 fuscus DSM 2262, GCF_000335475.2; Hyalangium minutum, GCF_000737315.1; Sandaracinus

742 amylolyticus, GCF_000737325.1; Archangium gephyra, GCF_001027285.1; Chondromyces

743 crocatus, GCF_001189295.1; Vulgatibacter incomptus, GCF_001263175.1; Labilithrix luteola,

744 GCF_001263205.1; Minicystis rosea, GCF_001931535.1; Melittangium boletus DSM 14713, 
GCF_002305855.1; Nannocystis exedens, GCF_002343915.1; Bradymonas sediminis,

GCF_003258315.1; Lujinxingia litoralis, GCF_003260125.1; Polyangium fumosum,

747 GCF_005144585.1; Persicimonas caeni, GCF_006517175.1; Myxococcus fulvus,

748 GCF_007991095.1; Pyxidicoccus fallax, GCF_012933655.1; Stigmatella aurantiaca,

749 GCF_900109545.1; Vitiosangium, GCF_003044305.1; Aggregicoccus, GCA_009659535.1;

750 Pajaroellobacter abortibovis, GCF_001931505.1; Byssovorax cruenta, GCA_001312805.1;

751 Enhygromyxa salina, GCF_002994615.1; Sorangium cellulosum B, GCF_000067165.1.

752 Zodletone genomes are labeled in blue bold text with their GenBank assembly accession number.

753 Class-level taxonomy is color coded as shown in the legend. The tracks underneath the tree

754 show: the ecosystem classification of the habitat from which the genomes originated, the

755 assembly genome size (grey bars), GC content (yellow bars), total number of genes in the

756 genome (cyan bars), and coding density (pink bars). The number of biosynthetic gene clusters

757 (BGCs in purple), proteases (in yellow), CAZymes (in green), and transcription factors (in blue)

758 encoded in each genome are shown as a heatmap with the color tone explained in the respective

759 legend. Following the heatmaps, the two outermost tracks denote the presence (filled squares)/

760 absence (empty squares) of the Myxococcota typical social lifestyle as evidenced by

761 experimental pure culture work (blue), and/or the machine learning approach (green) we used for

762 lifestyle prediction based on the informative set of $\mathrm{KO}$ numbers provided in Dataset 1.

763 Abbreviations: BGCs, biosynthetic gene clusters; GH, glycosyl hydrolases; PL, polysaccharide

764 lyases; CE, carbohydrate esterase; OCSs, one-component systems; TFs, transcription factors;

765 RR, response regulator; SF, sigma factor; TCSs, two-component systems; HK, histidine kinases;

766 and PP, phospho-relay proteins.

767 Figure 3. A cartoon depicting the thirteen pathways associated with Myxococcota social lifestyle 
examined in detail in this study. Myxococcus cells are shown as blue rods, while prey cells are depicted as grey cocci and rods. Pathways active during nutrient availability are shown above the

770 dotted lines, while those induced by starvation are shown below the dotted line. Each of the

771 pathways is shown in bold text within a color-coded outline. The same color code is used for the

772 group of genes in each pathway and in Table S6. For each pathway, a pie-chart for the number of

773 gene homologues identified in Zodletone genomes as a percentage of the total number of genes

774 in the pathway is shown in blue, while the $\%$ of gene homologues absent are shown in orange.

775 The size of the pie-chart is proportional to the number of genes in each pathway, and ranges from

7761 (FruA module) to 35 (the aggregation/ sporulation/ fruiting body formation module). Arrow

777 heads depict the effect where activation is shown as triangular arrowheads, and inhibition is

778 shown as horizontal line arrowheads. FruA* denotes the active form of FruA. Abbreviations:

779 EPS, exopolysaccharide; OME, outer membrane exchange.

780 Figure 4. Metabolic capabilities predicted in Zodletone novel Myxococcota. (A) Cartoon

781 depicting different metabolic capabilities encoded in the novel Zodletone genomes, with

782 capabilities predicted for different lineages shown as colored circles (all orders, black; Order

783 JAFGXQ01, green; Family JAFGIB01, purple). All substrates predicted to support growth are

784 denoted in boldface purple text within thick purple boxes. Fermentation end products are shown

785 in pink. Sites of substrate level phosphorylation are shown as red asterisks, as is the ATP

786 synthase complex (V), while sites of proton extrusion to the periplasm are shown as black

787 arrows. Electron transport components are shown in green. Paths of electron transfer are shown

788 as dotted black lines that start at electron donors (shown in boldface blue text) ending at terminal

789 electron acceptors (shown in boldface red text). Proton motive force generation, as well as

790 electron carrier recycling pathways associated with the operation of the WLP are shown in 
791 orange. Abbreviations: Apr, the enzyme complex adenylylsulfate reductase [EC:1.8.99.2]; APS,

792 adenylyl sulfate; Ara, arabinose; Dsr, dissimilatory sulfite reductase [EC:1.8.99.5]; EMP,

793 Embden Meyerhoff Paranas pathway; Frd $_{\text {ox/red }}$, Ferredoxin (oxidized/ reduced); Fru, fructose;

794 Gal, galactose; Glu, glucose; Hdr, heterodisulfide reductase complex; HexN, hexosamines;

795 HydABC, cytoplasmic [Fe Fe] hydrogenase; I, respiratory chain complex I; Man, mannose; Nrf,

796 nitrite reductase (cytochrome c-552); Otr, octaheme reductase; PhsABC, thiosulfate reductase;

797 PPP, pentose phosphate pathway; Pyr, pyruvate; Q pool, quinone pool; Qmo, quinone-interacting

798 membrane-bound oxidoreductase complex; RNF, membrane-bound RNF complex; RSH/RS-SR,

799 reduced/oxidized disulfide; TCA, tricarboxylic acid cycle; V, ATP synthase complex; WLP,

800 Wood Ljungdahl pathway; Xyl, xylose. (B) Maximum likelihood phylogenetic tree based on the

801 concatenated alignment of the alpha and beta subunits of dissimilatory sulfite reductase (DsrAB)

802 from family JAFGIB01 (bold red text) in relation to reference sequences. Reference sequences

803 from phyla other than Myxococcota are shown as wedged circles proportional to the number of

804 sequences. Myxococcota references are shown with their GenBank assembly accession number

805 in parentheses. Bootstrap support values are based on 100 replicates and are shown for nodes

806 with $>70 \%$ support. 
bioRxiv preprint doi: https://doi.org/10.1101/2021.07.06.451402; this version posted July 7, 2021. The copyright holder for this preprint (which

was not certified by peer review) is the author/funder, who has grantedbjoR xiv a license to display the preprint in perpetuity. It is made available undek aCC-BY-ND 4.0 Internationanlicense

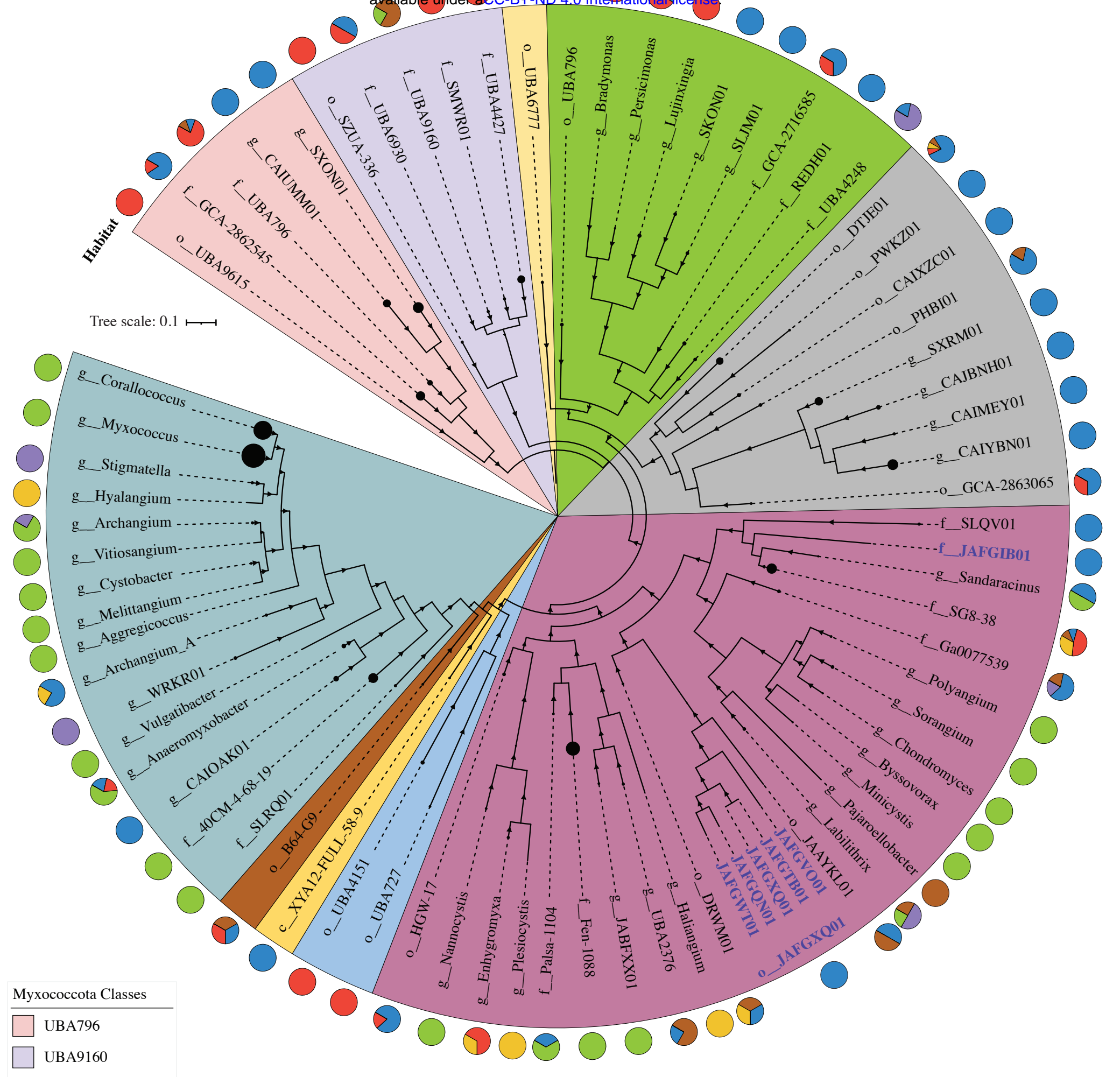

UBA6777

\begin{tabular}{ll} 
Bradymonadia & \multicolumn{2}{l}{ Habitat } \\
\cline { 2 - 2 } UBA9042 & $\square$ Engineered \\
Polyangia & $\square$ Freshwater \\
UBA727 & Host-associated \\
XYA12-FULL-58-9 & $\square$ Marine \\
B64-G9 & $\square$ Soil \\
Myxococcia & $\square$ Terrestrial non-soil
\end{tabular}


Tree scale: 0.1

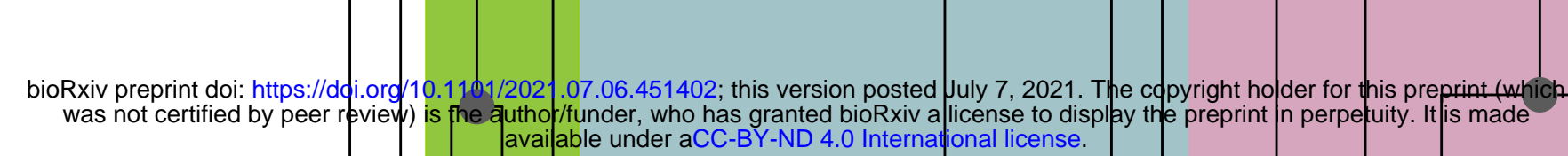

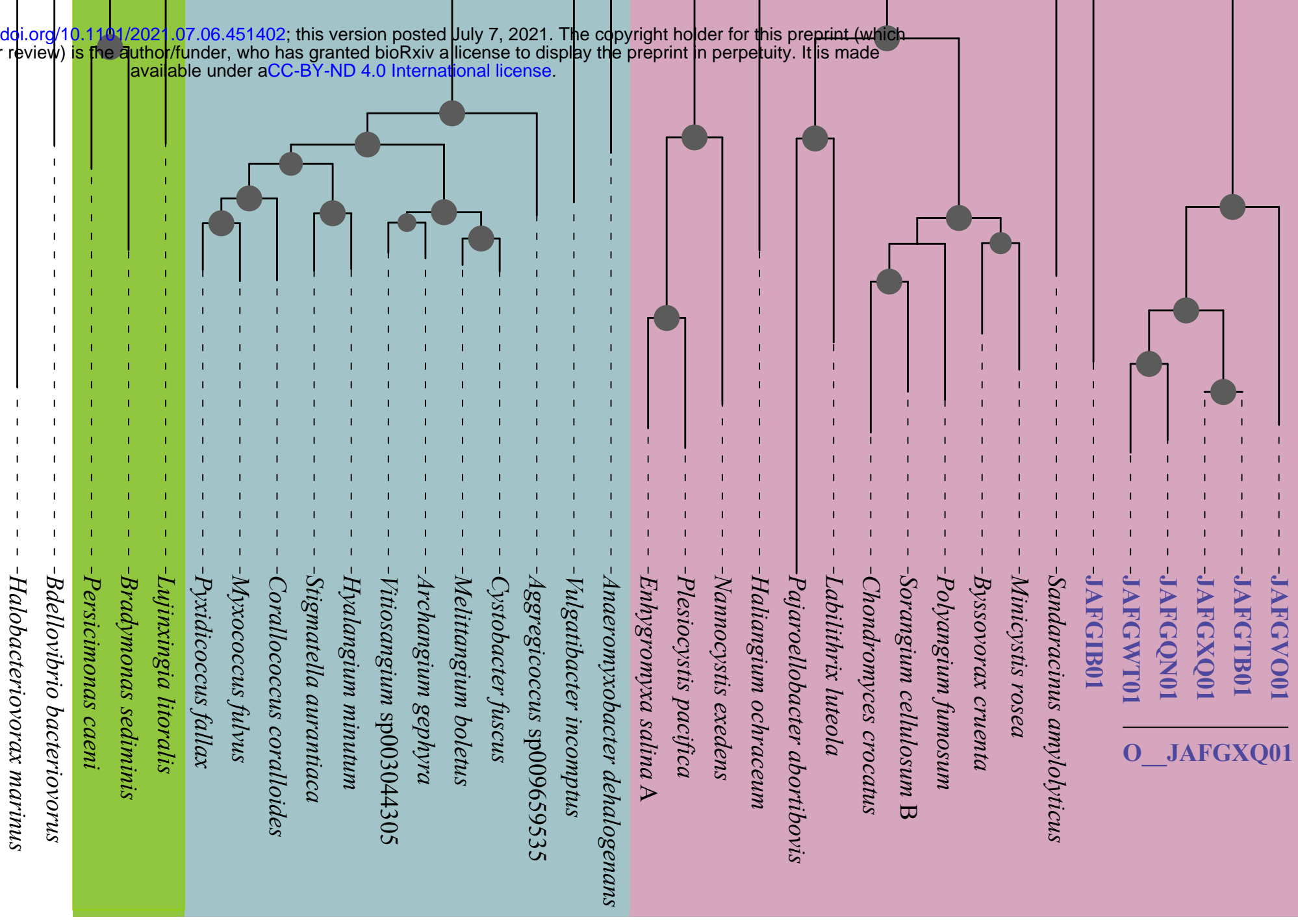

Isolation/ Binning source

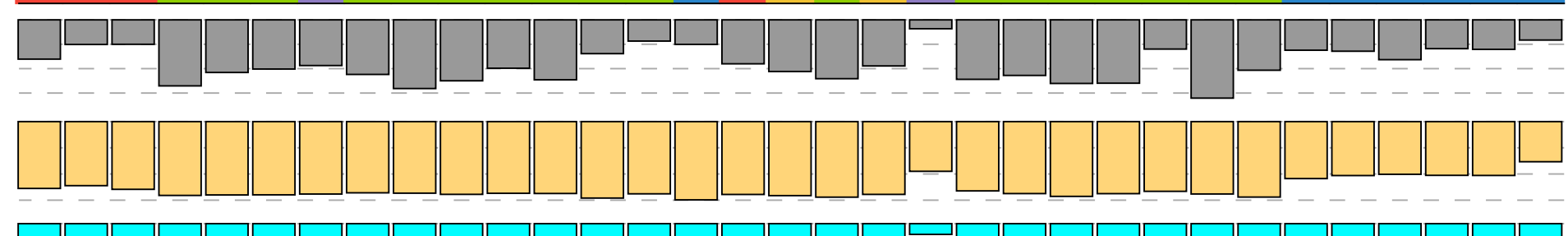

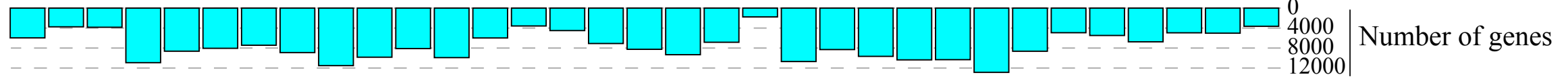

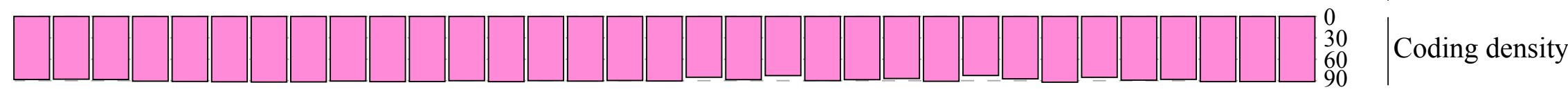
Genome size $(\mathrm{Mb})$

\begin{tabular}{|c|c|}
\hline Soil & Polyangia \\
\hline Terrestrial non-soil & Myxococcia \\
\hline Freshwater & Bradymonadia \\
\hline Marine & \\
\hline Host-associated & \\
\hline
\end{tabular}

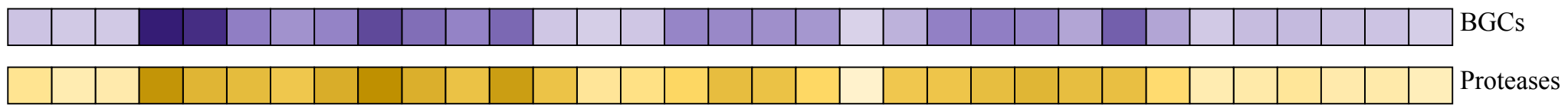
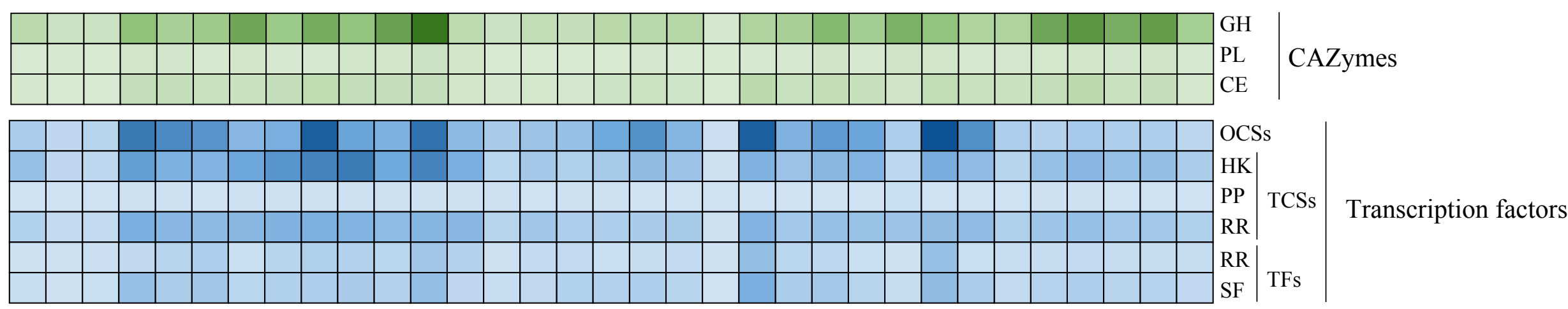

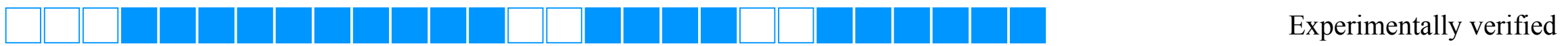
口 $\quad$ a $\quad \square \quad \square$ 
bioRxiv preprint doi: https://doi.org/10.1101/2021.07.06.451402; this version posted July 7, 2021. The copyright holder for this preprint (which was not certified by peer roview) is the author/funder, who has granted bioRxiv a license to display the preprint in perpetuity. It is made $\%$ of gene
Absent
Present

Fruiting body containing spores

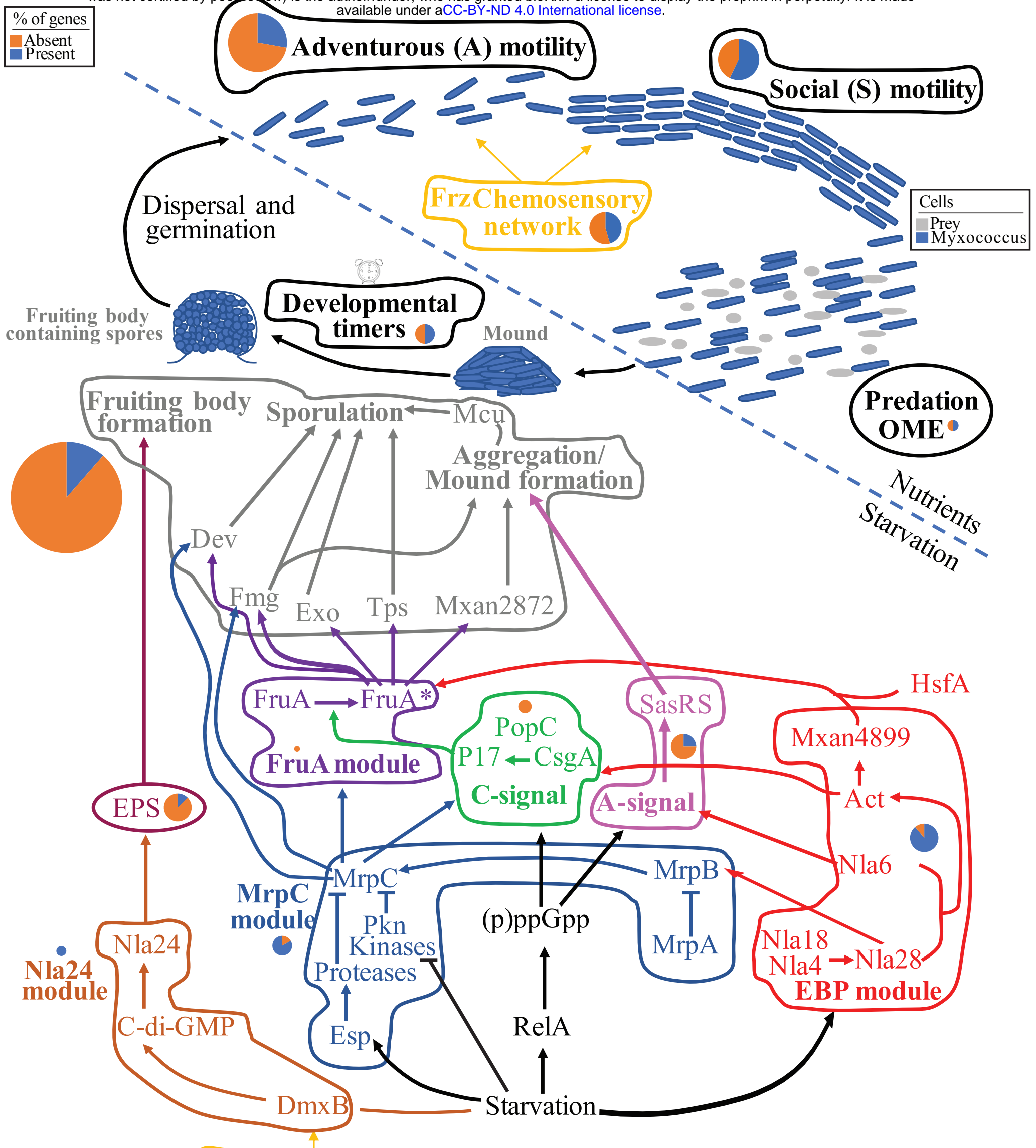

\section{Adventurous (A) motility}




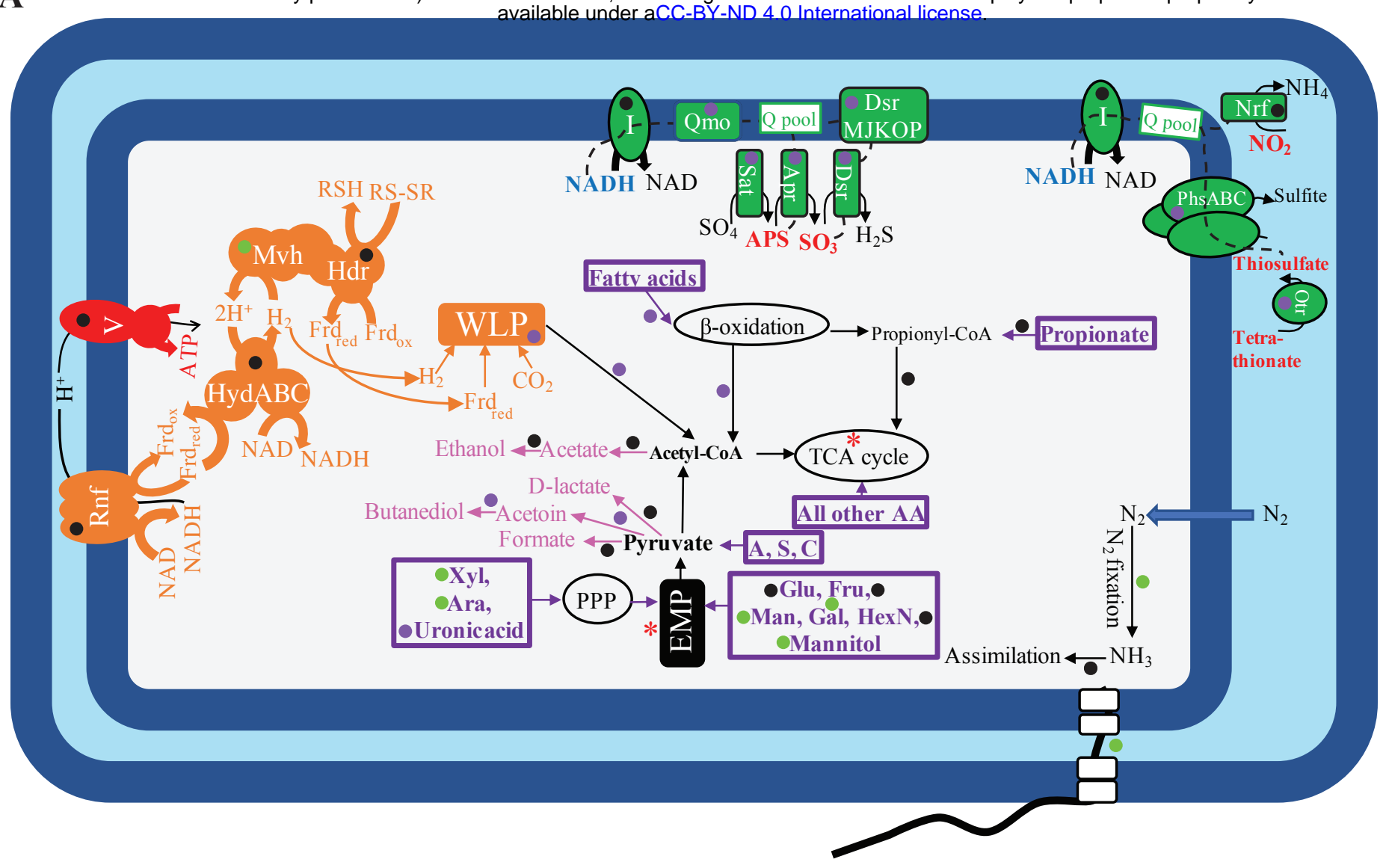

B

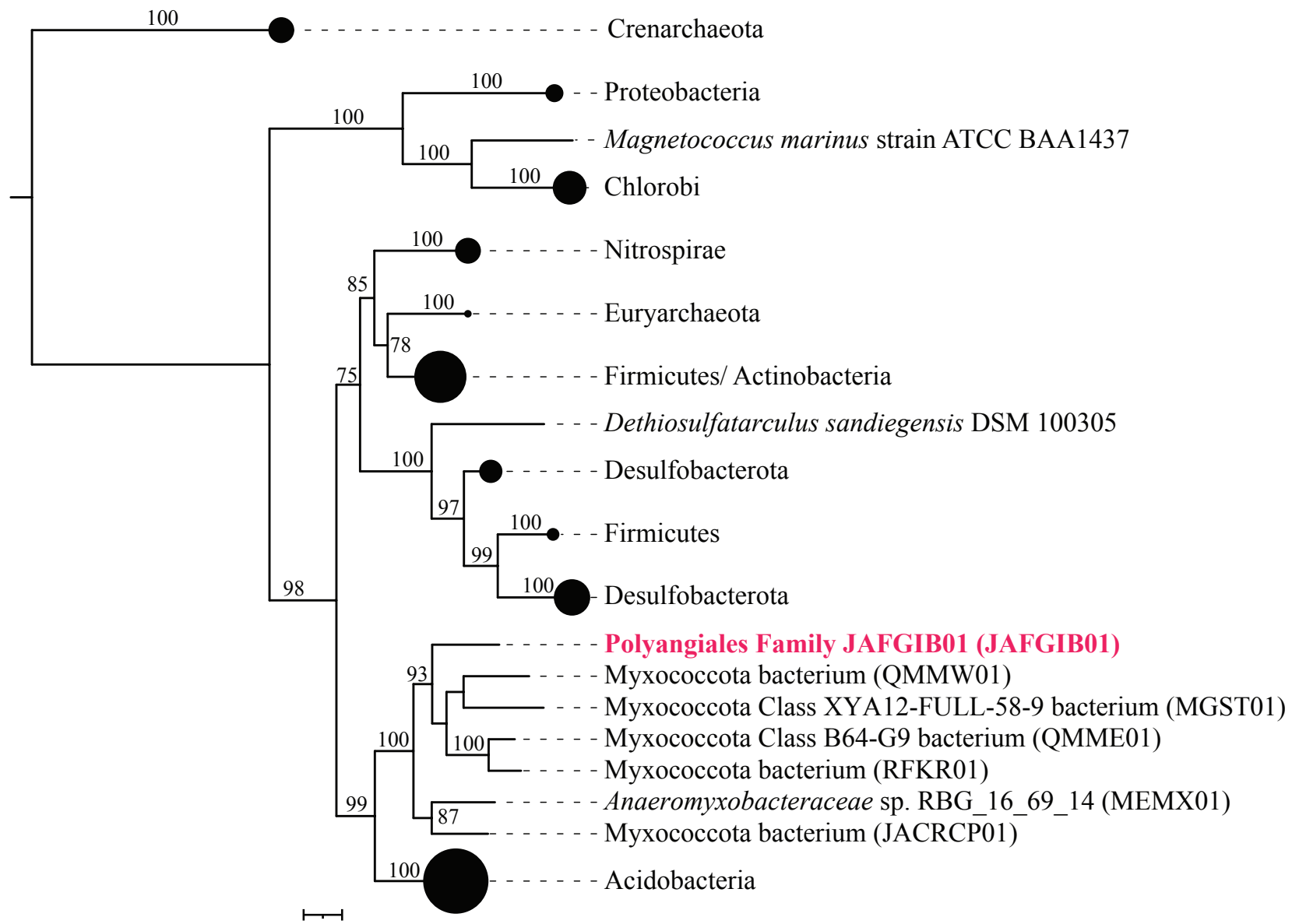


Table 1. Similarity statistics and GTDB classification of the MAGs analyzed in this study.

\begin{tabular}{|c|c|c|c|c|c|c|c|c|c|c|}
\hline \multirow[t]{2}{*}{ Bin name } & \multirow{2}{*}{$\begin{array}{c}\text { Assembly } \\
\text { accession } \\
\text { number }\end{array}$} & \multirow{2}{*}{$\begin{array}{c}\% \\
\text { completeness }\end{array}$} & \multirow{2}{*}{$\begin{array}{c}\% \\
\text { contamination }\end{array}$} & \multicolumn{3}{|c|}{ GTDB classification } & & \multicolumn{3}{|c|}{ Similarity statistics } \\
\hline & & & & Class & Order & Family & Genus & $\begin{array}{l}\text { RED }^{1} \\
\text { value }\end{array}$ & $\mathbf{A A I}^{2}$ & SGC $^{3}$ \\
\hline ZodW_Metabat.174 & JAFGVO01 & 91.24 & 3.26 & \multirow[t]{6}{*}{ Polyangia } & \multirow[t]{5}{*}{ JAFGXQ01 } & JAFGVO01 & JAFGVO01 & 0.490 & \multirow{5}{*}{$\begin{array}{l}38.1 \pm \\
0.9\end{array}$} & \multirow{5}{*}{$\begin{array}{l}40.1 \pm \\
5.62\end{array}$} \\
\hline Zod_Metabat.76 & JAFGQN01 & 94.84 & 3.87 & & & \multirow[t]{4}{*}{ JAFGXQ01 } & \multirow[t]{2}{*}{ JAFGQN01 } & 0.493 & & \\
\hline ZodW_Metabat.284 & JAFGWT01 & 89.08 & 3.87 & & & & & 0.489 & & \\
\hline Zod_Metabat.947 & JAFGTB01 & 94.19 & 3.23 & & & & \multirow[t]{2}{*}{ JAFGXQ01 } & 0.491 & & \\
\hline ZodW_Metabat.4 & JAFGXQ01 & 96.01 & 3.23 & & & & & 0.491 & & \\
\hline Zod_Metabat.169 & JAFGIB01 & 90.7 & 1.94 & & Polyangiales & JAFGIB01 & JAFGIB01 & 0.660 & $\begin{array}{c}40.1 \pm \\
1.7\end{array}$ & $\begin{array}{c}40.7 \pm \\
5.07\end{array}$ \\
\hline
\end{tabular}

${ }^{1}$ RED value: Relative Evolutionary Divergence values, based on placing the genomes in the Gtdb backbone bacterial tree (available at https://data.gtdb.ecogenomic.org/releases/release95/95.0/). RED values were used to confirm the novelty of the taxonomic lineage to which the genomes are assigned. Genomes are assigned to novel orders if their RED values fall between 0.62 and 0.46 , and novel families if their RED values fall between 0.62 and 0.77 .

${ }^{2}$ AAI: average amino acid identity calculated using the AAI calculator [http://enve-omics.ce.gatech.edu/]). The arbitrary AAI cutoffs used were $49 \%, 52 \%, 56 \%$, and $68 \%$ for class, order, family, and genus, respectively.

${ }^{3}$ SGC: shared gene content 
Table 2. Comparative genome analysis of pathways implicated in social behavior between Zodletone and cultured Myxococcota.

\begin{tabular}{|c|c|c|c|c|c|c|c|c|c|}
\hline $\begin{array}{l}\text { Process/ } \\
\text { pathway }\end{array}$ & $\begin{array}{c}\text { Major } \\
\text { function in } \\
\text { the social } \\
\text { lifestyle }\end{array}$ & 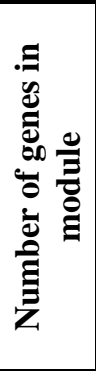 & \multicolumn{2}{|c|}{$\begin{array}{l}\text { Zodletone } \\
\text { lineages }\end{array}$} & \multicolumn{3}{|c|}{$\begin{array}{l}\text { Type species (non- } \\
\text { social) }\end{array}$} & \multicolumn{2}{|c|}{ Notes on homologues identified/missing in Zodletone genomes } \\
\hline MrpC module & $\begin{array}{l}\text { aggregation } \\
\text { and mound } \\
\text { formation } \\
\text { prior to } \\
\text { sporulation. }\end{array}$ & 8 & 75 & 62.5 & 75 & 75 & 87.5 & $\begin{array}{l}\text { - } 6 \text { homologues identified including } \\
\text { catalytic domains of serine/threonine } \\
\text { kinases }(\mathrm{n}=2) \text {, two component system } \\
\text { sensor histidine kinases }(\mathrm{n}=2) \text {, an } \\
\text { oligopeptide transporter }(\mathrm{n}=1) \text {, and a } \\
\text { DNA-binding transcriptional response } \\
\text { regulator of the } \mathrm{NtrC} \text { family }(\mathrm{n}=1) \text {. }\end{array}$ & $\begin{array}{l}\text { - MrpC, a transcription factor that } \\
\text { works cooperatively to control the start } \\
\text { of sporulation, is missing }\end{array}$ \\
\hline FruA module & & 1 & 0 & 0 & 0 & 0 & 0 & & $\begin{array}{l}\text { - FruA, a transcription factor that } \\
\text { works cooperatively to control the start } \\
\text { of sporulation, is missing. }\end{array}$ \\
\hline $\begin{array}{l}\text { EPS } \\
\text { production }\end{array}$ & $\begin{array}{l}\text { Exopolysaccha } \\
\text { ride } \\
\text { production } \\
\text { necessary for } \\
\text { the formation } \\
\text { of fruiting } \\
\text { bodies }\end{array}$ & 8 & 12.5 & 12.5 & 50 & 100 & 62.5 & $\begin{array}{l}\text { - } 1 \text { homologue identified with a sugar } \\
\text { transporter domain. }\end{array}$ & - 7 out 8 homologues missing \\
\hline
\end{tabular}




\begin{tabular}{|c|c|c|c|c|c|c|c|c|c|}
\hline C-signal & $\begin{array}{l}\text { Extracellular } \\
\text { signal } \\
\text { production }\end{array}$ & 3 & 0 & 0 & 0 & 0 & 0 & & $\begin{array}{l}\text { - All proteins in this module are } \\
\text { missing; CsgA encoding the actual C- } \\
\text { signal protein, the activating protease } \\
\text { PopC, and its inhibitor PopD. }\end{array}$ \\
\hline A-signal & & 8 & 25 & 25 & 75 & 75 & 75 & $\begin{array}{l}\text { - } 2 \text { homologues identified, both are } \\
\text { DNA-binding transcriptional response } \\
\text { regulators of the NtrC family. }\end{array}$ & $\begin{array}{l}\text { - A-signal production specific } \\
\text { homologues are missing. }\end{array}$ \\
\hline $\begin{array}{l}\text { Aggregation, } \\
\text { sporulation, } \\
\text { fruiting body } \\
\text { formation }\end{array}$ & $\begin{array}{l}\text { Gene } \\
\text { regulatory } \\
\text { networks } \\
\text { governing } \\
\text { sporulation }\end{array}$ & 35 & 11.4 & 11.4 & 40 & 22.9 & 42.9 & $\begin{array}{l}\text { - Only } 4 \text { homologues identified } \\
\text { ○ a sugar transporter } \\
\circ 3 \text { transcriptional regulators. }\end{array}$ & $\begin{array}{l}\text { - The majority of sporulation-specific } \\
\text { genes are missing } \\
\text { ○ the dev operon, } \\
\circ \text { CRISPR-Cas genes, } \\
\text { o the Exo and Nfs genes (both } \\
\text { involved in forming the spore } \\
\text { polysaccharide coat), } \\
\text { o the spore coat protein Tps, } \\
\text { o the putative FAD-binding } \\
\text { monooxygenase MXA2872, } \\
\text { o FruA-MrpC-regulated genes } \\
\text { (Fmg), } \\
\text { o mcu operon encoding a } \\
\text { chaperone/usher secretion system } \\
\text { important for spore-coat assembly). }\end{array}$ \\
\hline $\begin{array}{l}\text { Development } \\
\text { timers }\end{array}$ & $\begin{array}{l}\text { Fine tuning } \\
\text { and optimizing } \\
\text { the onset of } \\
\text { aggregation } \\
\text { and } \\
\text { sporulation }\end{array}$ & 6 & 50 & 50 & 83.3 & 83.3 & 83.3 & $\begin{array}{l}\text { - RodK and two of the RedCDEF, a } \\
\text { four-component system necessary for } \\
\text { controlling aggregation timing, were } \\
\text { identified. Homologues are similar to } \\
\text { sensor histidine kinase (n=2), and a } \\
\text { helix-turn-helix containing response } \\
\text { regulator. }\end{array}$ & $\begin{array}{l}\text { - Two of the RedCDEF, a four- } \\
\text { component system necessary for } \\
\text { controlling aggregation timing, were } \\
\text { missing. }\end{array}$ \\
\hline
\end{tabular}




\begin{tabular}{|c|c|c|c|c|c|c|c|c|c|}
\hline $\begin{array}{l}\text { Adventurous } \\
\text { (A) motility }\end{array}$ & Motility & 18 & 33.3 & 27.8 & 77.8 & 38.9 & 88.9 & $\begin{array}{l}3 \text { Glt complex genes and } 2 \mathrm{Agl} \\
\text { complex genes (similarity to } \\
\text { TolQR/ExbBD/MotAB-like channel) } \\
\text { were identified. }\end{array}$ & $\begin{array}{l}\text { AglZ that contributes to the assembly } \\
\text { of the inner membrane complex. } \\
\text { CglB, the lipoprotein interacting with } \\
\text { the substratum at focal adhesion sites } \\
\text { GltA, B, H, K (outer membrane beta } \\
\text { barrel structures that transport the } \\
\text { lipoprotein CglB to the external } \\
\text { surface) } \\
\text { AglQS (inner membrane complex) are } \\
\text { missing. }\end{array}$ \\
\hline $\begin{array}{l}\text { Outer } \\
\text { Membrane } \\
\text { Exchange } \\
\text { (OME) }\end{array}$ & $\begin{array}{l}\text { Sharing of } \\
\text { resources, kin- } \\
\text { recognition for } \\
\text { exclusion of } \\
\text { cheaters }\end{array}$ & 2 & 50 & 50 & 50 & 100 & 50 & $\begin{array}{l}\text { TraA partner, TraB, was identified } \\
\text { mainly because it contains an outer } \\
\text { membrane OmpA domain. }\end{array}$ & $\begin{array}{l}\text { TraA, the cell surface receptor, was not } \\
\text { identified in Zodletone genomes. }\end{array}$ \\
\hline
\end{tabular}

The process/pathway are color coded by module following the color code in Figure 3.

The cells with percentage of genes identified are color coded as follows: green, $>50 \%$ of the pathway was identified in the genome; yellow, $25-50 \%$ of the pathway was identified in the genome; pink, $<25 \%$ of the pathway was identified in the genome. 
Table 3. Catabolic capabilities deduced from genomic analysis of Zodletone Myxococcota in comparison to type species genomes available from KEGG organisms database. (Y, full pathway identified; n, full pathway missing; P, partial pathway identified).

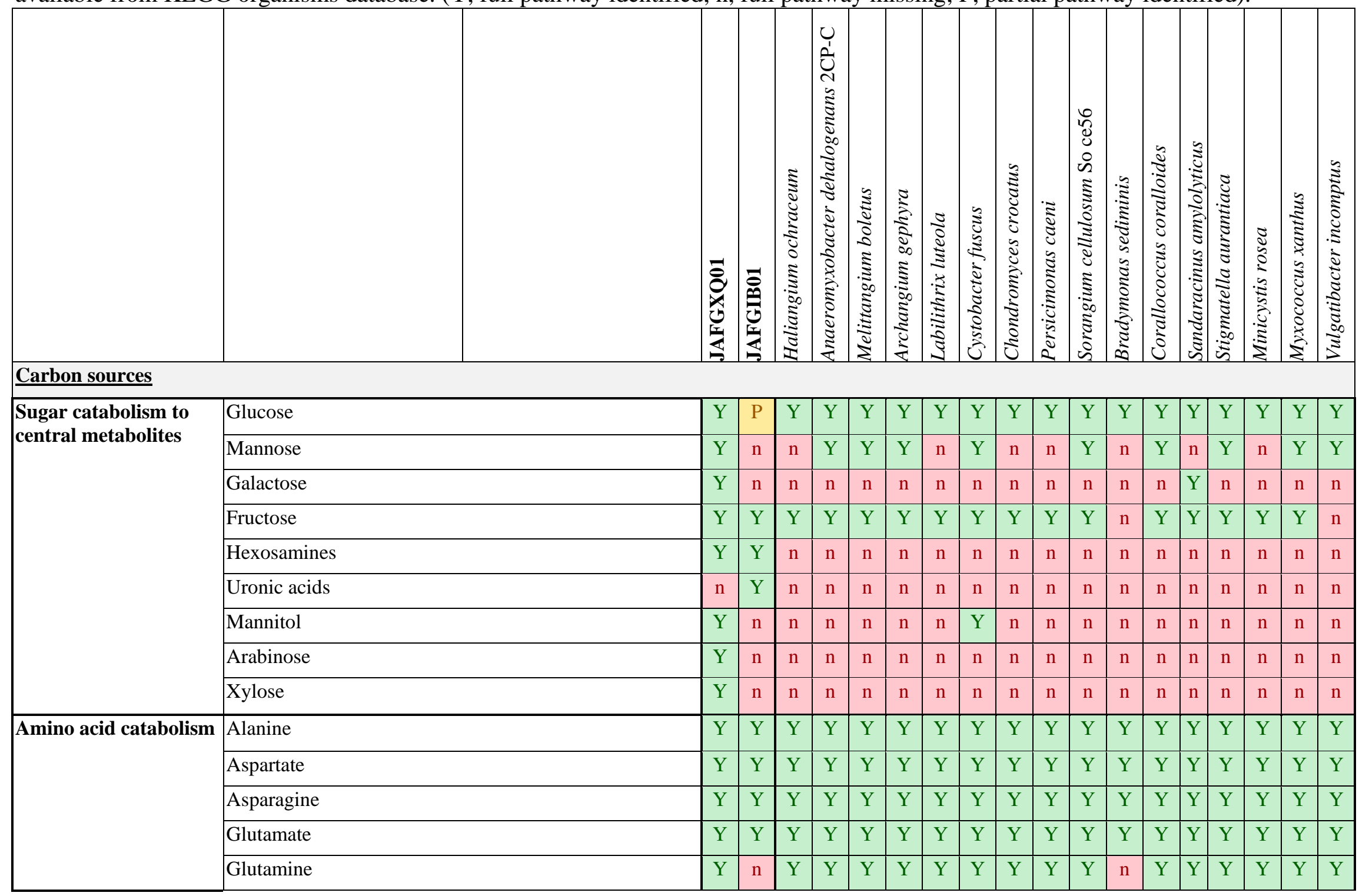




\begin{tabular}{|c|c|c|c|c|c|c|c|c|c|c|c|c|c|c|c|c|c|c|c|c|}
\hline & Glycine & & $\bar{Y}$ & $\mathrm{Y}$ & $\mathrm{Y}$ & $\mathrm{Y}$ & $\mathrm{Y}$ & $\mathrm{Y}$ & $\mathrm{Y}$ & $\mathrm{Y}$ & $\mathrm{Y}$ & $\mathrm{Y}$ & $\mathrm{Y}$ & $\mathrm{Y}$ & $\mathrm{Y}$ & $\mathrm{Y}$ & $\mathrm{Y}$ & $\mathrm{Y}$ & $\mathrm{Y}$ & $\bar{Y}$ \\
\hline & Cysteine & & $\overline{\mathrm{Y}}$ & $\mathrm{n}$ & $\mathrm{Y}$ & $\bar{Y}$ & $\bar{Y}$ & $\mathrm{Y}$ & $\mathrm{Y}$ & $\mathrm{Y}$ & $\mathrm{Y}$ & $\mathrm{Y}$ & $\mathrm{n}$ & $\mathrm{Y}$ & $\mathrm{Y}$ & $\mathrm{Y}$ & $\mathrm{Y}$ & $\mathrm{Y}$ & $\mathrm{Y}$ & $\bar{Y}$ \\
\hline & Methionine & & $\mathrm{n}$ & $\mathrm{n}$ & $\mathrm{Y}$ & $\mathrm{n}$ & $\mathrm{n}$ & $\mathrm{Y}$ & $\mathrm{Y}$ & $\mathrm{n}$ & $\mathrm{n}$ & $\mathrm{Y}$ & $\mathrm{n}$ & $\mathrm{n}$ & $\mathrm{n}$ & $\mathrm{n}$ & $\mathrm{Y}$ & $\mathrm{n}$ & $\mathrm{n}$ & $\mathrm{Y}$ \\
\hline & Serine & & $\mathrm{Y}$ & $\mathrm{n}$ & $\mathrm{Y}$ & $\mathrm{Y}$ & $\mathrm{Y}$ & $\mathrm{Y}$ & $\mathrm{Y}$ & $\mathrm{Y}$ & $\mathrm{Y}$ & $\mathrm{Y}$ & $\mathrm{Y}$ & $\mathrm{Y}$ & $\mathrm{Y}$ & $\mathrm{Y}$ & $\mathrm{Y}$ & $\mathrm{Y}$ & $\mathrm{Y}$ & $Y$ \\
\hline & Threonine & & $\bar{Y}$ & $\mathrm{n}$ & $\mathrm{Y}$ & $\bar{Y}$ & $\bar{Y}$ & $\mathrm{Y}$ & $\mathrm{Y}$ & $\mathrm{Y}$ & $\mathrm{Y}$ & $\mathrm{Y}$ & $\mathrm{Y}$ & $\bar{Y}$ & $\mathrm{Y}$ & $\mathrm{Y}$ & $\mathrm{Y}$ & $\mathrm{Y}$ & $\mathrm{Y}$ & $\mathrm{Y}$ \\
\hline & Valine & & $\mathrm{n}$ & $P$ & $\mathrm{P}$ & $\mathrm{P}$ & $\mathrm{P}$ & $\mathrm{P}$ & $\mathrm{P}$ & $\mathrm{P}$ & $\mathrm{P}$ & $\mathrm{P}$ & $\mathrm{P}$ & $\bar{P}$ & $\mathrm{P}$ & $\mathrm{P}$ & $\mathrm{P}$ & $\mathrm{P}$ & $\mathrm{P}$ & $\mathrm{P}$ \\
\hline & Leucine & & $\mathrm{n}$ & $P$ & $\mathrm{P}$ & $\mathrm{P}$ & $\mathrm{P}$ & $\mathrm{P}$ & $\mathrm{P}$ & $\mathrm{P}$ & $\mathrm{P}$ & $\mathrm{P}$ & $\mathrm{P}$ & $\mathrm{P}$ & $\mathrm{P}$ & $\mathrm{P}$ & $\mathrm{P}$ & $\mathrm{P}$ & $\mathrm{P}$ & $\mathrm{P}$ \\
\hline & Isoleucine & & $\mathrm{n}$ & $\mathrm{Y}$ & $\mathrm{P}$ & $\mathrm{P}$ & $\mathrm{P}$ & $\mathrm{P}$ & $\mathrm{Y}$ & $\mathrm{P}$ & $\mathrm{P}$ & $\mathrm{Y}$ & $\mathrm{P}$ & $\mathrm{Y}$ & $P$ & $P$ & $\mathrm{P}$ & $\mathrm{P}$ & $\mathrm{P}$ & $\mathrm{P}$ \\
\hline & Lysine & & $\mathrm{n}$ & $\mathrm{n}$ & $\mathrm{Y}$ & $\mathrm{Y}$ & $\mathrm{Y}$ & $\mathrm{Y}$ & $\mathrm{Y}$ & $\mathrm{n}$ & $\mathrm{Y}$ & $\mathrm{Y}$ & $\mathrm{Y}$ & $\bar{Y}$ & $\mathrm{Y}$ & $\mathrm{n}$ & $\mathrm{Y}$ & $\mathrm{Y}$ & $\mathrm{Y}$ & $\mathrm{Y}$ \\
\hline & Proline & & $n$ & $\mathrm{Y}$ & $\mathrm{Y}$ & $\bar{Y}$ & $\mathrm{Y}$ & $\mathrm{Y}$ & $\mathrm{Y}$ & $\mathrm{Y}$ & $\mathrm{Y}$ & $\mathrm{Y}$ & $\mathrm{Y}$ & $\mathrm{Y}$ & $\mathrm{Y}$ & $\mathrm{Y}$ & $\mathrm{Y}$ & $\mathrm{Y}$ & $\mathrm{Y}$ & $\mathrm{Y}$ \\
\hline & Arginine & & $\mathrm{n}$ & $\mathrm{Y}$ & $\mathrm{Y}$ & $\mathrm{n}$ & $\mathrm{n}$ & $\mathrm{n}$ & $\mathrm{n}$ & $\mathrm{n}$ & $\mathrm{n}$ & $\mathrm{n}$ & $\mathrm{n}$ & $\mathrm{n}$ & $\mathrm{n}$ & $n$ & $\mathrm{n}$ & $\mathrm{n}$ & $\mathrm{n}$ & $\mathrm{n}$ \\
\hline & Histidine & & $\mathrm{n}$ & $\mathrm{n}$ & $\mathrm{Y}$ & $\mathrm{Y}$ & $\mathrm{Y}$ & $\mathrm{Y}$ & $\mathrm{Y}$ & $\mathrm{Y}$ & $\mathrm{Y}$ & $\mathrm{Y}$ & $\mathrm{Y}$ & $\mathrm{Y}$ & $\mathrm{Y}$ & $\mathrm{Y}$ & $\mathrm{Y}$ & $\mathrm{Y}$ & $\mathrm{Y}$ & $\mathrm{Y}$ \\
\hline & Tyrosine & & $\mathrm{n}$ & $\mathrm{n}$ & $\mathrm{P}$ & $\mathrm{P}$ & $P$ & $\mathrm{P}$ & $\mathrm{P}$ & $\mathrm{P}$ & $\mathrm{P}$ & $\mathrm{P}$ & $\mathrm{P}$ & $P$ & $\mathrm{P}$ & $\mathrm{P}$ & $\mathrm{P}$ & $\mathrm{Y}$ & $\mathrm{P}$ & $\mathrm{P}$ \\
\hline & Tryptophan & & $\mathrm{n}$ & $\mathrm{n}$ & $\mathrm{P}$ & $\mathrm{P}$ & $\mathrm{n}$ & $\mathrm{P}$ & $\mathrm{n}$ & $\mathrm{n}$ & $\mathrm{n}$ & $\mathrm{P}$ & $\mathrm{n}$ & $\mathrm{n}$ & $\mathrm{P}$ & $n$ & $\mathrm{P}$ & $\mathrm{n}$ & $\mathrm{n}$ & $\mathrm{n}$ \\
\hline Fatty acids & Long chain & & $\bar{P}$ & $\bar{Y}$ & $\mathrm{Y}$ & $\bar{Y}$ & $\bar{Y}$ & $\mathrm{Y}$ & $\mathrm{Y}$ & $\mathrm{Y}$ & $\mathrm{Y}$ & $\mathrm{Y}$ & $\bar{Y}$ & $\bar{Y}$ & $\mathrm{Y}$ & $\mathrm{Y}$ & $\mathrm{Y}$ & $\mathrm{Y}$ & $\mathrm{Y}$ & $\bar{Y}$ \\
\hline $\mid \mathbf{d}$ & Lactate & & $\mathrm{n}$ & $\mathrm{n}$ & $\mathrm{Y}$ & $\mathrm{Y}$ & $\mathrm{n}$ & $\mathrm{Y}$ & $\mathrm{Y}$ & $\mathrm{n}$ & $\mathrm{n}$ & $\mathrm{Y}$ & $\mathrm{n}$ & $\mathrm{n}$ & $\mathrm{n}$ & $\mathrm{n}$ & $\mathrm{n}$ & $\mathrm{n}$ & $\mathrm{n}$ & $\mathrm{n}$ \\
\hline & Propionate & & $\bar{Y}$ & $\bar{Y}$ & $\mathrm{n}$ & $\mathrm{Y}$ & $\mathrm{n}$ & $\mathrm{n}$ & $\mathrm{Y}$ & $\mathrm{n}$ & $\mathrm{Y}$ & $\mathrm{Y}$ & $\mathrm{n}$ & $\bar{Y}$ & $\mathrm{n}$ & $\mathrm{n}$ & $\mathrm{n}$ & $\mathrm{Y}$ & $\mathrm{n}$ & $\mathrm{n}$ \\
\hline & Butanoate & & $\mathrm{n}$ & $\mathrm{n}$ & $\mathrm{n}$ & $\mathrm{Y}$ & $\mathrm{n}$ & $\mathrm{n}$ & $\mathrm{n}$ & $\mathrm{n}$ & $\mathrm{n}$ & $\mathrm{Y}$ & $\mathrm{n}$ & $\mathrm{n}$ & $\mathrm{n}$ & $\mathrm{n}$ & $\mathrm{n}$ & $\mathrm{n}$ & $\mathrm{n}$ & $\mathrm{n}$ \\
\hline Fermentation an & iration & & & & & & & & & & & & & & & & & & & \\
\hline Fate of pyruvate & Pyruvate to acetyl-CoA & $\begin{array}{l}\text { Pyruvate dehydrogenase } \\
{[\text { EC:1.2.4.1] }}\end{array}$ & $\bar{n}$ & $\bar{n}$ & $\mathrm{Y}$ & $\bar{Y}$ & $\bar{Y}$ & $\mathrm{Y}$ & $\mathrm{Y}$ & $\bar{Y}$ & $\mathrm{Y}$ & $\bar{Y}$ & $\bar{Y}$ & $\bar{Y}$ & $\mathrm{Y}$ & \begin{tabular}{|l|}
$Y$ \\
\end{tabular} & $\mathrm{Y}$ & $\mathrm{Y}$ & $\bar{Y}$ & $\bar{Y}$ \\
\hline & & \begin{tabular}{|l|} 
Pyruvate:ferrodoxin \\
oxidoreductase [EC:1.2.7.1]
\end{tabular} & $\mathrm{Y}$ & $\mathrm{Y}$ & $\mathrm{Y}$ & $\mathrm{Y}$ & $\mathrm{n}$ & $\mathrm{n}$ & $\mathrm{n}$ & $\mathrm{n}$ & $\mathrm{n}$ & $\mathrm{n}$ & $\mathrm{n}$ & $\mathrm{n}$ & $\mathrm{n}$ & $\mathrm{n}$ & $\mathrm{n}$ & $\mathrm{n}$ & $\mathrm{n}$ & $\mathrm{Y}$ \\
\hline & Acetyl-CoA to acetate & $\begin{array}{l}\text { Acetyl-CoA synthetase } \\
\text { [EC:6.2.1.1] }\end{array}$ & $\bar{Y}$ & $\bar{Y}$ & $\mathrm{Y}$ & $\bar{Y}$ & $\bar{Y}$ & $\mathrm{Y}$ & $\mathrm{Y}$ & $\mathrm{Y}$ & $\mathrm{Y}$ & $\mathrm{Y}$ & $\mathrm{Y}$ & $\bar{Y}$ & $\mathrm{Y}$ & $\mathrm{Y}$ & $\mathrm{Y}$ & $\mathrm{Y}$ & $\mathrm{Y}$ & $\mathrm{Y}$ \\
\hline & & $\begin{array}{l}\text { acetate---CoA ligase (ADP- } \\
\text { forming) subunit alpha } \\
{[\text { EC:6.2.1.13] }}\end{array}$ & $\mathrm{Y}$ & $\mathrm{Y}$ & $\mathrm{Y}$ & $\mathrm{n}$ & $\mathrm{n}$ & $\mathrm{n}$ & $\mathrm{Y}$ & $\mathrm{n}$ & $\mathrm{n}$ & $\mathrm{n}$ & $\mathrm{n}$ & $\mathrm{n}$ & $\mathrm{n}$ & $\mathrm{n}$ & $\mathrm{n}$ & $\mathrm{n}$ & $\mathrm{n}$ & $\mathrm{n}$ \\
\hline
\end{tabular}




\begin{tabular}{|c|c|c|c|c|c|c|c|c|c|c|c|c|c|c|c|c|c|c|c|c|}
\hline & & \begin{tabular}{|} 
succinyl-CoA:acetate CoA- \\
transferase [EC:2.8.3.18]
\end{tabular} & $\mathrm{n}$ & $\mathrm{n}$ & $\mathrm{n}$ & $\mathrm{Y}$ & $\mathrm{Y}$ & $\mathrm{n}$ & $\mathrm{n}$ & $\mathrm{n}$ & $\mathrm{n}$ & $\mathrm{n}$ & $\mathrm{n}$ & $\mathrm{n}$ & $\mathrm{n}$ & $\mathrm{n}$ & $\mathrm{n}$ & $\mathrm{n}$ & $\mathrm{n}$ & $\mathrm{n}$ \\
\hline & & $\begin{array}{l}\text { Phosphate acetyltransferase } \\
\text { and acetate kinase } \\
{[\text { EC:2.3.1.8 and EC:2.7.2.1] }}\end{array}$ & $\mathrm{n}$ & $\mathrm{n}$ & $\mathrm{n}$ & Y & $\mathrm{n}$ & $\mathrm{n}$ & $\mathrm{n}$ & $\mathrm{n}$ & $\mathrm{n}$ & $\mathrm{Y}$ & $\mathrm{n}$ & $\mathrm{n}$ & $\mathrm{n}$ & $\mathrm{n}$ & $\mathrm{n}$ & $\mathrm{n}$ & $\mathrm{n}$ & $\mathrm{n}$ \\
\hline & \multicolumn{2}{|c|}{ Ethanol production from acetate } & $\bar{Y}$ & $\mathrm{Y}$ & $\mathrm{n}$ & $\mathrm{n}$ & $\mathrm{Y}$ & $\mathrm{Y}$ & $\mathrm{Y}$ & $\mathrm{Y}$ & $\mathrm{Y}$ & $\mathrm{Y}$ & $\mathrm{Y}$ & $\mathrm{Y}$ & $\mathrm{Y}$ & $\mathrm{Y}$ & $\mathrm{Y}$ & $\mathrm{Y}$ & $\bar{Y}$ & $\mathrm{Y}$ \\
\hline & \multicolumn{2}{|c|}{ Ethanol production from acetyl-CoA } & $\mathrm{n}$ & $\mathrm{n}$ & $\mathrm{Y}$ & $\mathrm{n}$ & $\mathrm{n}$ & $\mathrm{n}$ & $\mathrm{n}$ & $\mathrm{n}$ & $\mathrm{n}$ & $\mathrm{Y}$ & $\mathrm{n}$ & $\mathrm{n}$ & $\mathrm{n}$ & $\mathrm{n}$ & $\mathrm{n}$ & $\mathrm{Y}$ & $\mathrm{n}$ & $\mathrm{n}$ \\
\hline & \multicolumn{2}{|c|}{ Formate production from pyruvate } & Y & $Y$ & $\mathrm{n}$ & $\mathrm{n}$ & $\mathrm{n}$ & $\mathrm{n}$ & $\mathrm{n}$ & $\mathrm{n}$ & $\mathrm{n}$ & $\mathrm{n}$ & $\mathrm{n}$ & $\mathrm{n}$ & $\mathrm{n}$ & $\mathrm{n}$ & $\mathrm{n}$ & $\mathrm{n}$ & $\mathrm{n}$ & $\mathrm{n}$ \\
\hline & \multicolumn{2}{|c|}{ D-lactate production from pyruvate } & Y & $Y$ & $\mathrm{Y}$ & $\mathrm{n}$ & $\mathrm{n}$ & $\mathrm{n}$ & $\mathrm{n}$ & $\mathrm{n}$ & $\mathrm{Y}$ & $\mathrm{Y}$ & $\mathrm{n}$ & $\mathrm{n}$ & $\mathrm{n}$ & $\mathrm{n}$ & $\mathrm{n}$ & $\mathrm{n}$ & Y & Y \\
\hline & \multicolumn{2}{|c|}{ L-lactate production from pyruvate } & $\mathrm{n}$ & $\mathrm{n}$ & $\mathrm{n}$ & $\mathrm{n}$ & $\mathrm{Y}$ & $\mathrm{Y}$ & $\mathrm{n}$ & $\mathrm{Y}$ & $\mathrm{n}$ & $\mathrm{n}$ & $\mathrm{Y}$ & $\mathrm{n}$ & $\mathrm{n}$ & $\mathrm{Y}$ & $\mathrm{Y}$ & $\mathrm{Y}$ & $\mathrm{n}$ & $\mathrm{n}$ \\
\hline & \multicolumn{2}{|c|}{ Acetoin production from pyruvate (via acetolactate) } & $\mathrm{n}$ & $\mathrm{Y}$ & $\mathrm{n}$ & $\mathrm{Y}$ & $\mathrm{n}$ & $\mathrm{n}$ & $\mathrm{n}$ & $\mathrm{n}$ & $\mathrm{n}$ & $\mathrm{n}$ & $\mathrm{Y}$ & $\mathrm{n}$ & $\mathrm{n}$ & $\mathrm{n}$ & $\mathrm{n}$ & $\mathrm{n}$ & $\mathrm{n}$ & $\mathrm{n}$ \\
\hline & \multicolumn{2}{|c|}{ Butanediol production from acetoin } & $\mathrm{n}$ & $\mathrm{Y}$ & $\mathrm{n}$ & $\bar{Y}$ & $\mathrm{n}$ & $\mathrm{n}$ & $\mathrm{n}$ & $\mathrm{n}$ & $\mathrm{n}$ & $\mathrm{n}$ & $\bar{Y}$ & $\mathrm{n}$ & $\mathrm{n}$ & $\mathrm{n}$ & $\mathrm{n}$ & $\mathrm{n}$ & $\mathrm{n}$ & $\mathrm{n}$ \\
\hline \multicolumn{3}{|l|}{ TCA cycle } & $\mathrm{Y}$ & $\mathrm{Y}$ & $\bar{Y}$ & $\mathrm{Y}$ & $\mathrm{Y}$ & $\mathrm{Y}$ & $\mathrm{Y}$ & $\mathrm{Y}$ & $\mathrm{Y}$ & $\mathrm{Y}$ & $\mathrm{Y}$ & $\mathrm{Y}$ & $\mathrm{Y}$ & $\mathrm{Y}$ & $\mathrm{Y}$ & $\mathrm{Y}$ & $\mathrm{Y}$ & $\mathrm{Y}$ \\
\hline \multirow[t]{8}{*}{ Respiration (aerobic) } & \multicolumn{2}{|c|}{ NADH dehydrogenase (complex I) } & $\bar{Y}$ & $\mathrm{Y}$ & $\bar{Y}$ & $\mathrm{Y}$ & $\mathrm{Y}$ & $\mathrm{Y}$ & $\mathrm{Y}$ & $\mathrm{Y}$ & $\mathrm{Y}$ & $\mathrm{Y}$ & $\mathrm{Y}$ & $\mathrm{Y}$ & $\mathrm{Y}$ & $\mathrm{Y}$ & $\mathrm{Y}$ & $\mathrm{Y}$ & $\bar{Y}$ & $\mathrm{Y}$ \\
\hline & \multicolumn{2}{|c|}{ Succinate dehydrogenase (complex II) } & $\mathrm{Y}$ & $\mathrm{Y}$ & $\mathrm{Y}$ & $\mathrm{Y}$ & $\mathrm{Y}$ & $\mathrm{Y}$ & $\mathrm{Y}$ & $\mathrm{Y}$ & $\mathrm{Y}$ & $\mathrm{Y}$ & $\mathrm{Y}$ & $\mathrm{Y}$ & $\mathrm{Y}$ & $\mathrm{Y}$ & $\mathrm{Y}$ & $\mathrm{Y}$ & $\mathrm{Y}$ & $\mathrm{Y}$ \\
\hline & \multicolumn{2}{|c|}{ Cytochrome c reductase (complex III) } & $\mathrm{n}$ & $\mathrm{n}$ & Y & $\mathrm{n}$ & $\mathrm{n}$ & $\mathrm{n}$ & Y & $\mathrm{n}$ & $\mathrm{n}$ & $\mathrm{n}$ & Y & $\mathrm{n}$ & $\mathrm{n}$ & $\mathrm{n}$ & $\mathrm{n}$ & $\mathrm{n}$ & $\mathrm{n}$ & $\mathrm{n}$ \\
\hline & \multicolumn{2}{|l|}{ Alternate Complex III } & $\mathrm{n}$ & $\mathrm{n}$ & $\mathrm{Y}$ & Y & Y & $\mathrm{Y}$ & Y & Y & $\mathrm{Y}$ & Y & Y & $\mathrm{Y}$ & Y & Y & $\mathrm{Y}$ & $\mathrm{Y}$ & Y & Y \\
\hline & \multirow[t]{3}{*}{ Complex IV } & $\begin{array}{l}\text { Cytochrome bd respiratory } \\
\text { O2 reductase (high O2 } \\
\text { affinity, complex IV) }\end{array}$ & $\bar{Y}$ & $\bar{Y}$ & $\mathrm{n}$ & $\bar{Y}$ & $\mathrm{n}$ & $\mathrm{Y}$ & $\mathrm{Y}$ & $\mathrm{n}$ & $\mathrm{Y}$ & $\mathrm{Y}$ & $\bar{Y}$ & $\mathrm{n}$ & $\mathrm{Y}$ & $\mathrm{n}$ & $\mathrm{n}$ & $\mathrm{Y}$ & $\bar{Y}$ & $\bar{Y}$ \\
\hline & & $\begin{array}{l}\text { Cytochrome } \mathrm{C} \text { oxidase aa } 3 \\
\text { type (low } \mathrm{O} 2 \text { affinity) }\end{array}$ & $\mathrm{n}$ & $\mathrm{n}$ & $\mathrm{Y}$ & $\mathrm{Y}$ & $\mathrm{Y}$ & $\mathrm{Y}$ & $\mathrm{Y}$ & $\mathrm{Y}$ & $\mathrm{Y}$ & $\mathrm{Y}$ & $\mathrm{Y}$ & $\mathrm{Y}$ & $\mathrm{Y}$ & $\mathrm{Y}$ & $\mathrm{Y}$ & $\mathrm{Y}$ & $\mathrm{Y}$ & $\mathrm{Y}$ \\
\hline & & $\begin{array}{l}\text { Cytochrome C oxidase cbb3 } \\
\text { type (high } \mathrm{O} 2 \text { affinity) }\end{array}$ & $\mathrm{n}$ & $\mathrm{n}$ & $\mathrm{n}$ & $\bar{Y}$ & $\mathrm{n}$ & $\mathrm{Y}$ & $\mathrm{Y}$ & $\mathrm{n}$ & $\mathrm{n}$ & $\mathrm{Y}$ & $\mathrm{n}$ & $\mathrm{Y}$ & $\mathrm{n}$ & $\mathrm{Y}$ & $\mathrm{n}$ & $\mathrm{Y}$ & $\bar{Y}$ & $\mathrm{Y}$ \\
\hline & ATP synthase (complex V) & F-type & $\mathrm{Y}$ & $\mathrm{Y}$ & $\mathrm{Y}$ & Y & Y & $\mathrm{Y}$ & Y & Y & $\mathrm{Y}$ & Y & Y & $\mathrm{Y}$ & $\mathrm{Y}$ & $\mathrm{Y}$ & $\mathrm{Y}$ & $\mathrm{Y}$ & Y & $\mathrm{Y}$ \\
\hline \multirow{4}{*}{$\begin{array}{l}\text { Dissimilatory nitrite } \\
\text { reduction to ammonia } \\
\text { (DNRA) }\end{array}$} & \multirow[t]{2}{*}{ Nitrate reductase } & $\begin{array}{l}\text { Periplasmic NapAB } \\
\text { [EC:1.9.6.1] }\end{array}$ & $\mathrm{n}$ & $\mathrm{n}$ & $\mathrm{n}$ & $\mathrm{n}$ & $\mathrm{n}$ & $\mathrm{Y}$ & $\mathrm{n}$ & $\mathrm{n}$ & $\mathrm{n}$ & $\mathrm{Y}$ & Y & $\mathrm{Y}$ & $\mathrm{n}$ & $\mathrm{n}$ & $\mathrm{n}$ & $\mathrm{n}$ & $\mathrm{n}$ & $\mathrm{n}$ \\
\hline & & $\begin{array}{l}\text { Membrane-bound NarGHI } \\
\text { [EC:1.7.5.1] }\end{array}$ & $\mathrm{n}$ & $\mathrm{n}$ & $\mathrm{n}$ & $\mathrm{Y}$ & $\mathrm{n}$ & $\mathrm{n}$ & $\mathrm{n}$ & $\mathrm{n}$ & $\mathrm{n}$ & $\mathrm{n}$ & $\mathrm{n}$ & $\mathrm{n}$ & $\mathrm{n}$ & $\mathrm{n}$ & $\mathrm{n}$ & $\mathrm{n}$ & $\mathrm{n}$ & $\mathrm{n}$ \\
\hline & \multirow[t]{2}{*}{ Nitrite reductase } & $\begin{array}{l}\text { NirBD; NADH } \\
\text { [EC:1.7.1.15] }\end{array}$ & $\mathrm{n}$ & $\mathrm{n}$ & $\mathrm{n}$ & $\mathrm{n}$ & $\mathrm{n}$ & $\mathrm{n}$ & $\mathrm{n}$ & Y & $\mathrm{n}$ & $\mathrm{n}$ & Y & $\mathrm{n}$ & $\mathrm{n}$ & $\mathrm{Y}$ & $\mathrm{n}$ & $\mathrm{n}$ & $\mathrm{n}$ & $\mathrm{n}$ \\
\hline & & $\begin{array}{l}\text { NrfAH; Cytochrome; } \\
\text { ammonia-forming } \\
{[\text { [EC:1.7.2.2] }}\end{array}$ & $\mathrm{Y}$ & $\mathrm{Y}$ & $\mathrm{n}$ & $\mathrm{Y}$ & $\mathrm{n}$ & $\mathrm{Y}$ & $\mathrm{n}$ & $\mathrm{n}$ & $\mathrm{n}$ & $\mathrm{n}$ & $\mathrm{Y}$ & $\mathrm{n}$ & $\mathrm{Y}$ & $\mathrm{n}$ & $\mathrm{n}$ & $\mathrm{n}$ & $\mathrm{Y}$ & $\mathrm{Y}$ \\
\hline
\end{tabular}




\begin{tabular}{|c|c|c|c|c|c|c|c|c|c|c|c|c|c|c|c|c|c|c|c|}
\hline Denitrification & & $\mathrm{n}$ & $\mathrm{n}$ & $\mathrm{n}$ & $\mathrm{P}$ & $\mathrm{n}$ & $\mathrm{n}$ & $\mathrm{n}$ & $\mathrm{n}$ & $\mathrm{n}$ & $\mathrm{n}$ & $\mathrm{n}$ & $\mathrm{n}$ & $\mathrm{n}$ & $\mathrm{n}$ & $\mathrm{n}$ & $\mathrm{n}$ & $\mathrm{n}$ & $\mathrm{n}$ \\
\hline \multirow{4}{*}{$\begin{array}{l}\text { Dissimilatory sulfate } \\
\text { reduction }\end{array}$} & Sulfate adenylyltransferase & $\mathrm{n}$ & $\bar{Y}$ & $\mathrm{n}$ & $\mathrm{n}$ & $\mathrm{n}$ & $\mathrm{n}$ & $\mathrm{n}$ & $\mathrm{n}$ & $\mathrm{n}$ & $\mathrm{n}$ & $\mathrm{n}$ & $\bar{n}$ & $\mathrm{n}$ & $\mathrm{n}$ & $\mathrm{n}$ & $\mathrm{n}$ & $\mathrm{n}$ & $\mathrm{n}$ \\
\hline & Adenylylsulfate reductase & $\mathrm{n}$ & $\bar{Y}$ & $\mathrm{n}$ & $\mathrm{n}$ & $\mathrm{n}$ & $\mathrm{n}$ & $\mathrm{n}$ & $\mathrm{n}$ & $\mathrm{n}$ & $\mathrm{n}$ & $\mathrm{n}$ & $\mathrm{n}$ & $\mathrm{n}$ & $\mathrm{n}$ & $\mathrm{n}$ & $\mathrm{n}$ & $\mathrm{n}$ & $\mathrm{n}$ \\
\hline & $\begin{array}{l}\text { Quionone interacting membrane bound oxidoreductase } \\
\text { complex (QmoABC) }\end{array}$ & $\mathrm{n}$ & $\mathrm{Y}$ & $\mathrm{n}$ & $\mathrm{n}$ & $\mathrm{n}$ & $\mathrm{n}$ & $\mathrm{n}$ & $\mathrm{n}$ & $\mathrm{n}$ & $\mathrm{n}$ & $\mathrm{n}$ & $\mathrm{n}$ & $\mathrm{n}$ & $\mathrm{n}$ & $\mathrm{n}$ & $\mathrm{n}$ & $\mathrm{n}$ & $\mathrm{n}$ \\
\hline & Dissimilatory sulfite reductase & $\mathrm{n}$ & $\mathrm{Y}$ & $\mathrm{n}$ & $\mathrm{n}$ & $\mathrm{n}$ & $\mathrm{n}$ & $\mathrm{n}$ & $\mathrm{n}$ & $\mathrm{n}$ & $\mathrm{n}$ & $\mathrm{n}$ & $\mathrm{n}$ & $\mathrm{n}$ & $\mathrm{n}$ & $\mathrm{n}$ & $\mathrm{n}$ & $\mathrm{n}$ & $\mathrm{n}$ \\
\hline $\begin{array}{l}\text { Tetrathionate } \\
\text { respirattion }\end{array}$ & Octaheme tetrathionate reductase (Otr) & $\mathrm{n}$ & $\mathrm{Y}$ & $\mathrm{n}$ & $\mathrm{n}$ & $\mathrm{n}$ & $\mathrm{n}$ & $\mathrm{n}$ & $\mathrm{n}$ & $\mathrm{n}$ & $\mathrm{n}$ & $\mathrm{n}$ & $\mathrm{n}$ & $\mathrm{n}$ & $\mathrm{n}$ & $\mathrm{n}$ & $\mathrm{n}$ & $\mathrm{n}$ & $\mathrm{n}$ \\
\hline \begin{tabular}{|l|} 
Thiosulfate \\
disproportionation
\end{tabular} & Thiosulfate reductase (PhsABC) & $\mathrm{n}$ & $\bar{Y}$ & $\mathrm{n}$ & $\mathrm{Y}$ & $\mathrm{n}$ & $\mathrm{n}$ & $\mathrm{n}$ & $\mathrm{n}$ & $\mathrm{n}$ & $\mathrm{n}$ & $\mathrm{n}$ & $\mathrm{n}$ & $\mathrm{n}$ & $\mathrm{n}$ & $\mathrm{n}$ & $\mathrm{n}$ & $\mathrm{n}$ & $\mathrm{n}$ \\
\hline Thiosulfate oxidation & SOX complex & $\mathrm{n}$ & $\mathrm{n}$ & $\mathrm{n}$ & $\mathrm{Y}$ & $\mathrm{n}$ & $\mathrm{n}$ & $\mathrm{n}$ & $\mathrm{n}$ & $\mathrm{n}$ & $\mathrm{n}$ & $\mathrm{n}$ & $\mathrm{n}$ & $\mathrm{n}$ & $\mathrm{n}$ & $\mathrm{n}$ & $\mathrm{n}$ & $\mathrm{n}$ & $\mathrm{n}$ \\
\hline Sulfite oxidation & SoeABC & $\mathrm{n}$ & $\mathrm{n}$ & $\mathrm{n}$ & $\mathrm{Y}$ & $\mathrm{n}$ & $\mathrm{n}$ & $\mathrm{n}$ & $\mathrm{n}$ & $\mathrm{n}$ & $\mathrm{n}$ & $\mathrm{n}$ & $\mathrm{n}$ & $\mathrm{n}$ & $n$ & $\mathrm{n}$ & $\mathrm{n}$ & $\mathrm{n}$ & $\mathrm{n}$ \\
\hline Sulfide oxidation & sulfide:quinone oxidoreductase [EC:1.8.5.4] & $\mathrm{n}$ & $\mathrm{n}$ & $\mathrm{Y}$ & $\mathrm{Y}$ & Y & $\mathrm{Y}$ & $\mathrm{n}$ & Y & $\mathrm{Y}$ & $\mathrm{Y}$ & $\mathrm{n}$ & $\mathrm{n}$ & $\mathrm{Y}$ & $\mathrm{n}$ & $\mathrm{Y}$ & $\mathrm{n}$ & $\mathrm{Y}$ & $\mathrm{n}$ \\
\hline
\end{tabular}

